\title{
ipen
}

AUTARQUIA ASSOCIADA À UNIVERSIDADE DE SÃO PAULO

\section{PURIFICAÇÃO E CARACTERIZAÇÃO DE PROTEASES DO VENENO DA Pseudechis australis E DE SEUS INIBIDORES ENDÓGENOS}

BRUNO BAESSA CHAGAS

Dissertação apresentada como parte dos requisitos para obtenção do Grau de Mestre em Ciências na Área de Tecnologia Nuclear Aplicações

Orientador:

Prof. Dr. Patrick Jack Spencer 


\title{
INSTITUTO DE PESQUISAS ENERGÉTICAS E NUCLEARES
}

Autarquia associada à Universidade de São Paulo

\section{PURIFICAÇÃO E CARACTERIZAÇÃO DE PROTEASES DO VENENO DA Pseudechis australis E DE SEUS INIBIDORES ENDÓGENOS}

\author{
BRUNO BAESSA CHAGAS
}

\author{
Dissertação apresentada como parte dos \\ requisitos para obtenção do Grau de \\ Mestre em Ciências na Área de Tecnologia \\ Nuclear - Aplicações \\ Orientador: \\ Prof. Dr. Patrick Jack Spencer
}

Versão Corrigida

Versão Original disponível no IPEN

São Paulo

2015 


\section{AGRADECIMENTOS}

Agradeço primeiramente a Deus por toda força, proteção e coragem que me deu para poder concluir mais essa etapa

À minha família por todo o suporte.

À Dra. Nanci do Nascimento por ter sido a primeira pessoa com quem falei e por ter dado a oportunidade de fazer parte do grupo.

Ao Dr. Patrick Jack Spencer que além de ser meu orientador, foi um grande amigo nesses anos, que me aceitou mesmo eu não sendo da área biológica, me ajudando em tudo que precisei

À minha grande e mais que confiável amiga Tamara que me ajudou sempre que precisei, tendo a paciência de ensinar quantas vezes fosse preciso, tirando todas as dúvidas que surgiam, me dando conselhos em todos os experimentos

Ao meu amigo Vincent pelos conselhos e pelas várias ajudas em discussões de métodos e pelos ensinamentos

À minha amiga Paula que me aturou todo esse tempo, suportando meus momentos de impaciência

Ao meu amigo Fernando pelas várias horas de conversa e distração

Ao Johnny por ajudar sempre que tinha duvidas

Ao Dr. Daniel Pimenta por dispor de seu laboratório e nos ajudar com os experimentos

A todos os amigos de laboratório Samuel, Danielle, Marcela, Podé, Ed Carlos, Karina, pela colaboração e pelas gargalhadas. 
Às funcionárias do IPEN, Arlete e Ruth pelos conselhos e pelas risadas.

À CAPES pelo apoio financeiro 
"E na doçura da amizade, que haja risos e o partilhar de prazeres.

Pois no orvalho de pequenas coisas, o coração encontra sua manhã e se sente refrescado"

(Khalil Gibran) 


\section{PURIFICAÇÃO E CARACTERIZAÇÃO DE PROTEASES DO VENENO DA Pseudechis australis E DE SEUS INIBIDORES ENDÓGENOS}

\section{Bruno Baessa Chagas}

\section{RESUMO}

A Austrália é um país cuja fauna é um repositório de potenciais novos biofármacos, pois se encontram no continente os animais mais mortais do planeta, dentre eles, as serpentes. A serpente Pseudechis australis (Mulga snake) é a maior serpente venenosa da Austrália e tem ampla distribuição geográfica. Os venenos de serpentes são complexas misturas com proteínas e peptídeos que apresentam uma variedade de atividades biológicas. Devido à riqueza de seus componentes, várias moléculas encontradas no veneno vêm sendo utilizadas com fins terapêuticos, como agentes anticoagulantes ou analgésicos. Apesar dessas informações, existem poucos dados disponíveis sobre os componentes específicos deste veneno. O presente trabalho tem como objetivo isolar e caracterizar as proteases desse veneno, ainda não descritas, um primeiro passo para compreender o papel destas enzimas no processo de envenenamento, assim como seus inibidores endógenos. Estes desempenham uma função protetora da glândula de veneno, inibindo a ação das enzimas in loco, prevenindo assim a degradação do tecido glandular por estas toxinas. $O$ interesse nestes inibidores está relacionado ao seu potencial uso na terapia de diversas doenças como distúrbios da coagulação, hipertensão e câncer. 


\title{
PURIFICATION AND CHARACTERIZATION OF Pseudechis australis VENOM PROTEASES AND ENDOGENOUS INHIBITORS
}

\author{
Bruno Baessa Chagas
}

\begin{abstract}
Australia is a natural repository of some of the deadliest venomous animals on the planet and, as such, a potential source for new toxin-derived drugs. Venomous snakes are among the many potential sources of new promising compounds. Snake venoms are complex mixtures of proteins and peptides that exhibit a variety of biological activities which all are directed towards subduing the prey and/or aggressor. These toxins act disturbing homeostasis, affecting neural transmission, hemostasis, tissue integrity as well as other body functions. Such a a wide array of specific activities has turned snake toxins into successful drugs used for therapeutic purposes, as anticoagulants or analgesic agents. Unlike snake venoms from other parts of the world, there are few records on the venom composition of Australian snakes, turning these into potential sources of new bioactive molecules for drug design. This study aims to isolate and characterize the yet undescribed proteases of the venom of $\mathrm{P}$. australis as well as their endogenous inhibitors, as a first step in understanding the role of these enzymes in the envenoming process.
\end{abstract}




\section{SUMÁRIO}

1 . INTRODUÇÃO

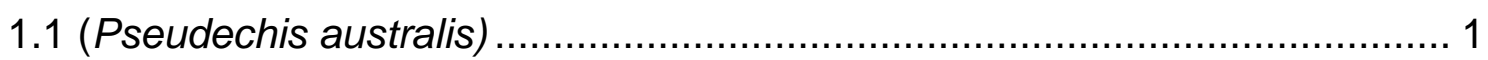

1.2 Veneno da Pseudechis australis .......................................................... 1

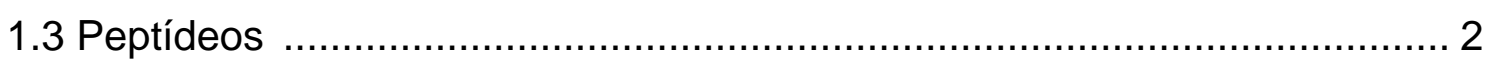

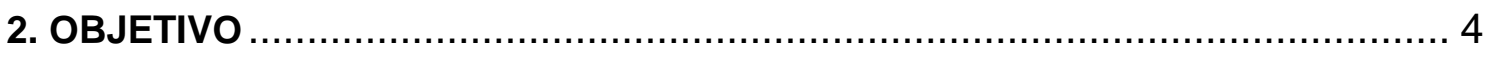

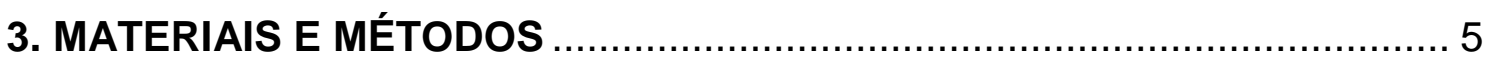

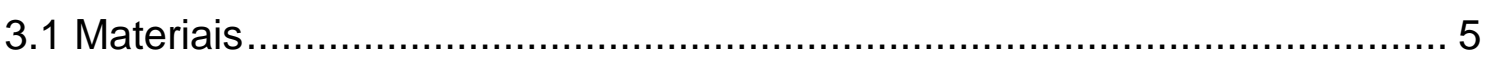

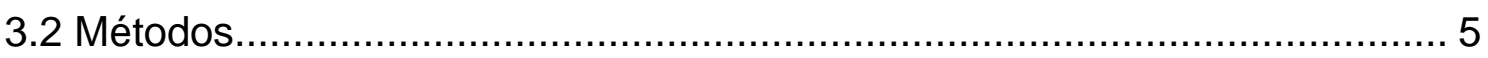

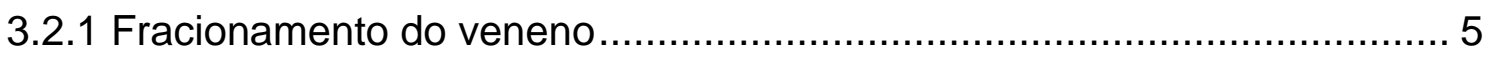

3.2.2 Cromatografia de exclusão molecular .................................................... 5

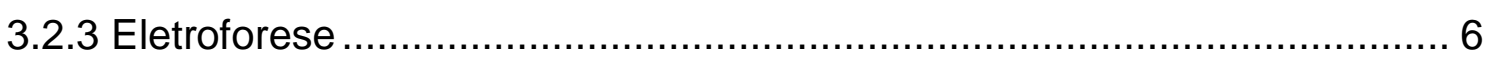

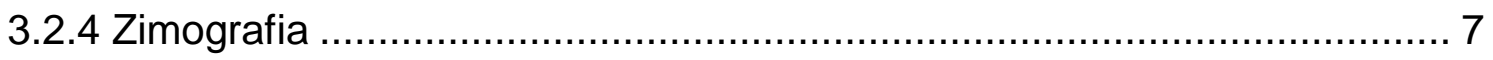

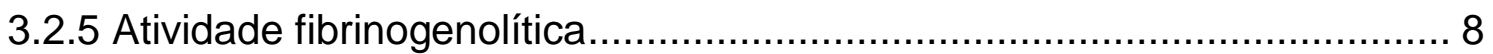

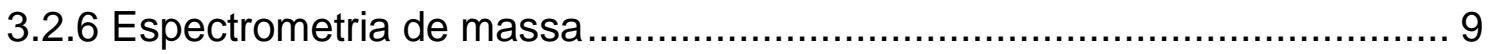

3.2.6.1 Sequenciamento de novo automático da fração peptídica ..................... 9

3.2.6.2 Identificação de proteínas das frações de alta massa do veneno ......... 10

3.2.7 Padronização de um método fluorimétrico para deteç̧ão e quantificação de atividade caseinolítica ........................................................................ 10

3.2.8 Sequenciamento de novo de peptídeos naturais do veneno de $P$. australis

4. RESULTADOS

4.1 Cromatografia de exclusão molecular ................................................. 12

4.2 Eletroforese Gel SDS PAGE 15\% .................................................. 13

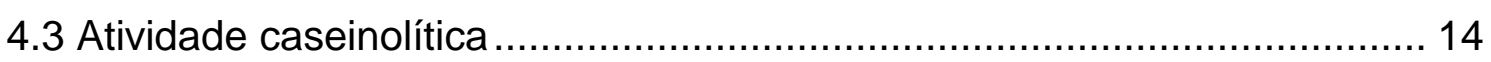

4.4 Zimografia sem e com agentes inibidores .............................................. 14

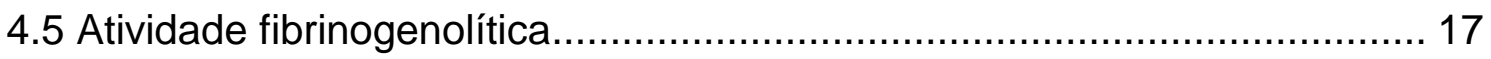

4.6 Espectrometria de massa e cromatografia de exclusão molecular ............. 21

4.6.1 Sequenciamento de novo de peptídeos naturais do veneno de Pseudechis

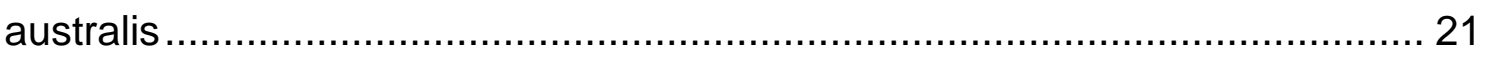

4.6.2 Identificação de proteínas das frações de alta massa do veneno ............ 23 


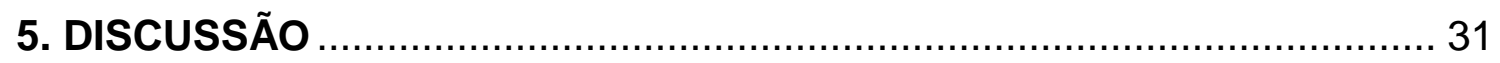

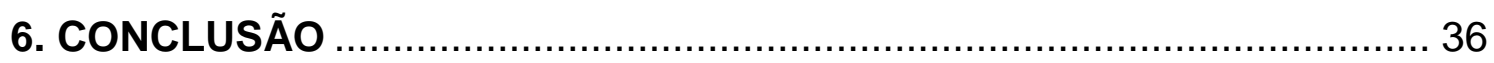

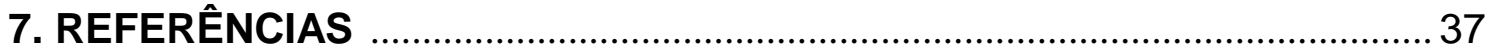




\section{LISTA DE FIGURAS}

Figura 1 - Pseudechis australis em seu habitat 1

Figura 2 - Cromatografia de exclusão molecular de $20 \mathrm{mg}$ do veneno total da Pseudechis australis

Figura 3 - Gel SDS PAGE 15\% com as três frações coletadas da cromatografia de exclusão molecular.

Figura 4 - Atividade caseinolítica com os três picos coletados da cromatografia de exclusão molecular 14 Figura 5 - Atividade gelatinolítica dos picos I, II e III da cromatografia de exclusão molecular 15

Figura 6 - Atividade gelatinolítica dos picos I, II e III utilizando inibidor de metaloproteases 15

Figura 7 - Atividade gelatinolítica do pico II com e sem inibidor de metaloprotease 16

Figura 8 - Atividade gelatinolítica do pico II com e sem inibidor de serinoprotease

Figura 9 - Atividade fibrinogenolítica do pico II com tempo de até $2 \mathrm{~h}$ 18

Figura 10 - Atividade fibrinogenolítica do pico II com tempo de até 24h...........19

Figura 11 - Atividade fibrinogenolítica do pico II utilizando inibidor de serinoproteases (PMSF)

Figura 12 - Espectro de massas da fragmentação do íon pai sequenciado automaticamento pelo PEAKS 22

Figura 13 - Cromatografia de exclusão molecular de $30 \mathrm{mg}$ do veneno total da Pseudechis australis 23 


\section{LISTA DE TABELAS}

Tabela 1 -Sequências obtida pelo sequenciamento de novo

Tabela 2 - Identificação com PEAKS de proteínas nas frações de exclusão molecular do veneno de Pseudechis australis por espectrometria de massas LCMS/MS de peptídeos trípticos. 24

Tabela 3 - Fármacos que são derivados dos venenos de serpentes.. .33 


\section{INTRODUÇÃO}

\subsection{Pseudechis australis (MULGA SNAKE)}

A Austrália é um país rico em biodiversidade e tem abundância de animais peçonhentos, pois na ilha é possível encontrar os tipos mais letais de águasvivas, aranhas, polvos e cobras além do ornitorrinco, um dos poucos mamíferos peçonhentos já descritos. A família Elapidae (sub-família Acantophiinae) está representada por 90 espécies (57,7\% de um total de 156 espécies de serpentes descritas no continente australiano (WILLIAMS, WÜSTER \& FRY, 2006).

A Pseudechis australis (Figura 1), da família é a maior serpente venenosa da Austrália alcançando 2,7 metros. Esta espécie apresenta uma ampla distribuição geográfica em habitats de savanas áridas, semiáridas e tropicais abrangendo quase todo o continente, exceto a costa leste e extremo sul (AUSTRALIAN REPTILE PARK, 2014).

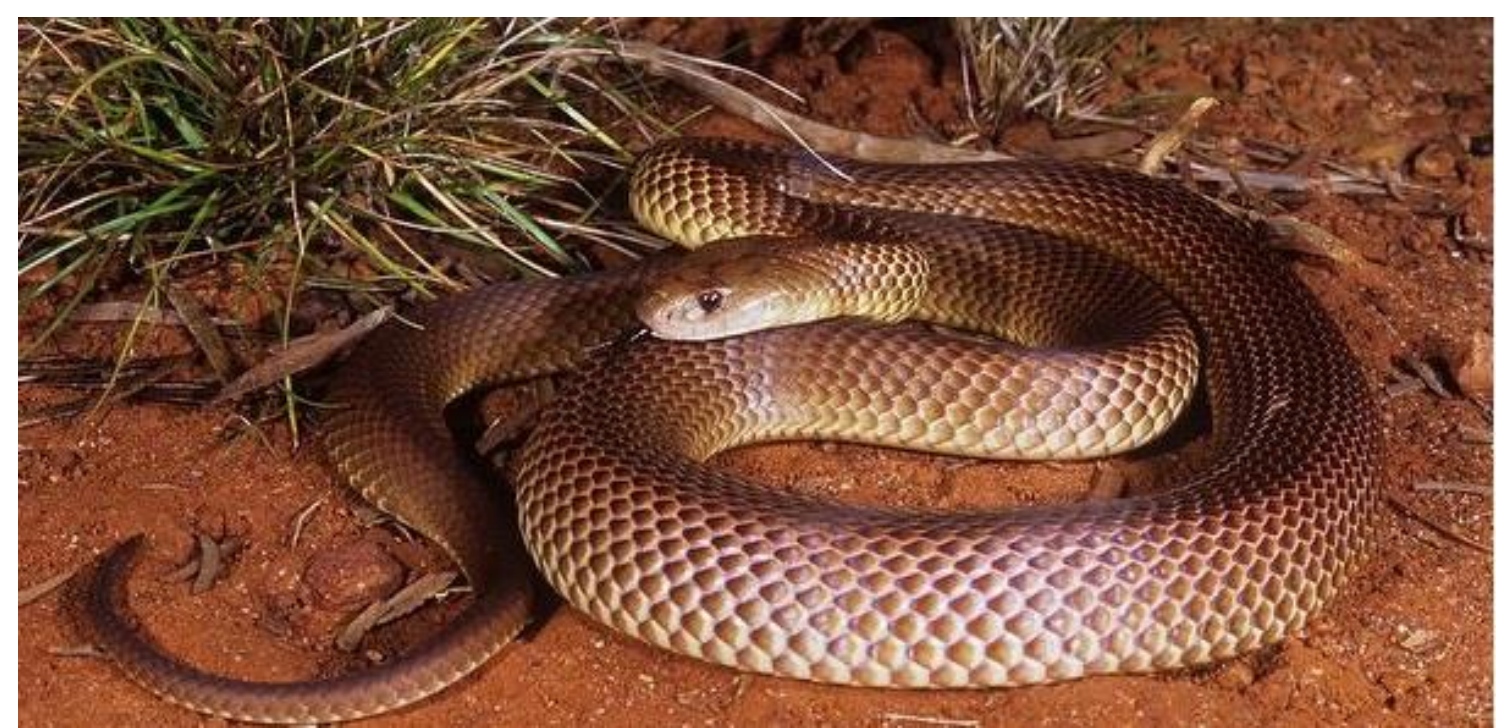

Figura 1 - Pseudechis australis em seu habitat (www.arkive.org/, 2015)

\subsection{VENENO DE Pseudechis australis.}

Os venenos das elapidaes australianas estão entre os mais tóxicos do mundo e contêm vários componentes que tem como alvo a sistema circulatório, a sinalização neuromuscular e o tecido muscular (BIRREL et al., 2007).

Embora o veneno de Pseudechis australis seja considerado menos tóxico quando comparado a outros venenos de elapidaes australianas, a quantidade de 
veneno secretada pela serpente é maior do que a de qualquer outra serpente australiana e os efeitos já descritos incluem: necrose, sintomas sistêmicos nãoespecíficos, anosmia, anemia hemolítica e lesão renal aguda. Seu veneno tem uma grande variedade de toxinas incluindo miotoxinas, toxinas anticoagulantes, neurotoxinas, hemotoxinas e peptídeos natriuréticos (JOHNSTON et al., 2013).

A mionecrose presente na picada de serpente pode ser efeito direto da ação de fospfolipases $A_{2}\left(P L A_{2}\right)$ miotóxicas na membrana plasmática das células musculares ou fruto da ação de metaloproteinases hemorrágicas que afetam a integridade de vasos sanguíneos, causando isquemia e consequente morte do tecido. Além das toxinas acima descritas, o veneno de Pseudechis australis contem neurotoxinas com ação pré e pós-sináptica. Estas atuam no bloqueio da transmissão neural, bloqueando a liberação de neurotransmissores (présináptica) ou pela ligação competitiva com os receptores de acetilcolina (póssináptico) impedindo a transmissão neuromuscular e causando morte por asfixia (CUNHA \& MARTINS, 2012). Já as toxinas anticoagulantes, depletam o fibrinogênio circulante, impedindo a coagulação (FUNASA, 2001), atuando de forma sinérgica com as hemorraginas,causando sangramentos nas mais diversas partes do corpo.

\subsection{PEPTÍDEOS E INIBIDORES}

Além dos componentes protéicos, os venenos são compostos por misturas únicas de peptídeos adaptados naturalmente para interferir nos sistemas vitais da presa ou vítima (CALVETE et al., 2009). Dentre as diversas toxinas peptídicas já descritas estão os peptídeos natriuréticos que tem um papel importante em vários processos fisiológicos dentro mamíferos incluindo os sistemas cardiovascular e endócrino e a homeostase renal. Várias propriedades dos peptídeos natriuréticos, incluindo os seus efeitos sobre a diurese, natriurese, a relaxação de vasos e sua ação anti-mitogénica, os torna candidatos ideais para a terapia de distúrbios cardiovasculares (PIERRE et al., 2006).

Várias moléculas isoladas dos venenos ofídicos estão sendo usadas para fins terapêuticos como 0 Batroxobin $\AA$ e 0 Ancrod®, utilizados como anticoagulantes em cirurgias cardíacas e outras estão sendo investigadas como o Enpak, potente analgésico isolado do veneno de cascavel brasileira que é um 
forte candidato a substituto da morfina. Com o advento das técnicas bioquímicas mais sensíveis e precisas, como espectrometria de massa, resinas cromatográficas de alta resolução e detectores ultravioleta mais sensíveis, tornou-se possível identificar e caracterizar componentes minoritários dos venenos que antes, devido a sua baixa concentração e/ou à baixa resolução dos sistemas de purificação, passavam despercebidos.

Muito se tem publicado a respeito dos componentes protéicos de venenos de serpentes. No entanto, salvo exceções, pouco se sabe a respeito dos componentes de baixo peso molecular presentes nestas secreções. Foram isoladas miotoxinas peptídicas como a crotamina (GONÇALVES, 1956; LAURE, 1975), miotoxina A (BIEBER e NEDELKOV, 1997), peptídeos potenciadores de bradicinina (BPPs) que permitiram o desenvolvimento de fármacos antihipertensivos (LUFT, 2008), assim como inibidores do tipo Kunitz de serinoproteases (RITONJA et al., 1983) e inibidores de metaloproteases (FRANCIS e KAISER, 1993). Estes estudos apontam para uma rica diversidade de moléculas bioativas de baixa massa molecular nos venenos, pouco estudadas, justificando uma investigação mais detalhada, focada em peptídeos. O interesse nestas moléculas está relacionado ao potencial uso destes inibidores de protease como agentes terapêuticos contra diversas patologias, como distúrbios da coagulação e modulação da atividade de metaloproteinases, moléculas estas envolvidas com tumorigenêse (ARGAWAL et al., 2010) e outros processos patológicos como inflamação crônica e distúrbios neurológicos (KLEIN e BISCHOFF, 2010). De acordo com a literatura (FRANCIS E KAISER, 1993, MARQUES-PORTO, 2008) estes inibidores, além de exercerem uma função na predação e defesa da serpente, teriam um papel protetor na glândula de veneno, evitando a ação deletéria das proteases no tecido onde são secretadas e armazenadas. 
2. OBJETIVO

Isolar e caracterizar as proteases e seus potenciais inibidores endógenos do veneno de Pseudechis australis. 


\section{MATERIAL E MÉTODOS}

\subsection{MATERIAL}

Foi utilizado um pool de veneno total da espécie Pseudechis australis oriundo do banco de venenos do Centro de Biotecnologia e cedido pela Empresa Venom Supplies (Austrália).

\subsection{MÉTODOS}

\subsubsection{FRACIONAMENTO DO VENENO}

Foram pesados $20 \mathrm{mg}$ do veneno total de Pseudechis australis dissolvidos em 1.2 mL de tampão bicarbonato de amônio 100mM pH 7,0, aplicado em uma membrana Centricon® DE $10 \mathrm{kDa}$, que foi centrifugada sob refrigeração a $4^{\circ} \mathrm{C}$ por 50 minutos com rotação de 1000 G, sendo esse processo repetido duas vezes. As moléculas de alta massa molecular retidas pela membrana (>10 kDa) foram submetidas a cromatografia de exclusão molecular e a fração não retida pela membrana foi congelada $a-80^{\circ} \mathrm{C}$ e liofilizada para análise em espectrometria de massa.

\subsubsection{CROMATOGRAFIA DE EXCLUSÃO MOLECULAR}

A cromatografia por exclusão promove uma distribuição seletiva e dinâmica das moléculas a serem separadas entre dois líquidos, a fase móvel presente dentro dos poros da fase estacionária e a fase móvel externa aos poros. A fase estacionária, insolúvel na fase móvel, é comumente um polímero ou um gel e apresenta poros de tamanhos bem controlados, que regulam a entrada e a saída das moléculas que podem permear parcialmente ou completamente dentro da fase estacionária, sem ter qualquer interação com ela, princípio esse diferente dos mecanismos que governam as outras modalidades de cromatografia (COLLINS, 2011). As moléculas que não têm penetração são excluídas e saem primeiro, agrupadas, da coluna, enquanto as que penetram completamente 
também saem junto no volume total da eluição.

Após a concentração da amostra, foi realizada uma cromatografia de exclusão molecular. A fração retida na membrana (>10 kDa) foi completada com tampão de bicarbonato de amônio para $1.2 \mathrm{~mL}$. Para a realização da cromatografia foram injetados $1 \mathrm{~mL}$, em uma coluna Superdex 75 10/300 GL (GE Healthcare) conectada e a um sistema Äkta purifier do mesmo fabricante, previamente equilibrada com o tampão acima. $O$ fluxo foi de $0,5 \mathrm{~mL} / \mathrm{min}$ e a absorvância do eluato foi monitorada a 220 e $280 \mathrm{~nm}$. Foram coletadas frações de $1 \mathrm{~mL}$

\subsubsection{ELETROFORESE}

A eletroforese consiste na migração de moléculas ionizadas, de acordo com suas cargas e massas moleculares em um campo elétrico. Moléculas com carga negativa migram para o pólo positivo (ânodo) e moléculas com carga positiva migram para o pólo negativo (cátodo). A carga líquida das moléculas é função somatória das cargas dos aminoácidos que as constituem em um dado pH. Em razão das proteínas serem substâncias anfóteras, ou seja, capazes de adquirirem carga positiva ou negativa em função do pH, é indispensável manter constante o pH do meio durante a eletroforese, pelo uso de soluções-tampão.

Foi realizado um gel de eletroforese sendo que para o gel de resolução utilizou-se $15 \%$ de poliacrilamida e o gel de empilhamento foi preparado com uma concentração de $4 \%$ de poliacrilamida. Após o fracionamento por exclusão molecular foram coletados $50 \mu \mathrm{L}$ de cada "pool" que foram diluídos em $10 \mu \mathrm{L}$ de tampão de amostra sem agente redutor (glicerol, SDS 10\%, Tris $1 \mathrm{M}, \mathrm{pH} 6,8$ e azul de bromofenol).

Posteriormente, $15 \mu \mathrm{L} /$ poço da amostra foram aplicados no gel e submetidos à eletroforese sob uma voltagem constante de $100 \mathrm{~V}$. O gel foi então corado utilizando-se o corante Coomassie Blue G-250. 


\subsubsection{ZIMOGRAFIA}

É uma técnica proteômica eletroforética que permite a visualização do número e tamanho aproximado de enzimas em amostras biológicas, com base na degradação de um substrato co-polimerizado juntamente com os géis de eletroforese. No caso das proteases, utilizam-se como substrato a gelatina, caseína, fibronectina e colágeno, entre outros. Esta técnica é muito útil na análise da composição de proteases de amostras biológicas complexas, pois a visualização dessas proteases depende diretamente da atividade proteolítica. A zimografia com substrato de gelatina é uma técnica amplamente usada no estudo de metaloproteases, especialmente as metaloproteases de matriz (MMPs).

Outras vantagens desta técnica incluem a sensibilidade na faixa de picogramas e o uso de reagentes baratos e acessíveis. Esta técnica consiste em co-polimerizar o substrato de gelatina em um gel comum de SDS-PAGE. Como o substrato está preso nos poros do gel, ele não migra quando é aplicada a corrente eléctrica durante a eletroforese. A amostra biológica é desnaturada por SDS, porém não reduzida, e então aplicada no gel para separação. O tampão de solubilização da amostra não deve conter $\beta$-mercaptoetanol, para evitar a quebra das pontes dissulfeto. Após a corrida eletroforética, as proteases separadas são renaturadas dentro do gel, por lavagens repetidas com um detergente não-iónico, como o Triton X-100, que substitui o SDS do gel. O gel é então incubado em um tampão adequado, permitindo que as proteases renaturadas realizem a digestão do substrato em uma zona ao redor de sua posição no gel. Estas zonas são visualizadas ao corar o gel com Coomassie Blue, pois o gel inteiro fica azul e as áreas de digestão aparecem como zonas transparentes. As proteases são então identificadas comparando as áreas digeridas com os padrões de peso molecular e/ou fazendo testes de inibição com inibidores específicos para certas classes de proteases (DAVIS, 2012)

Para o gel de zimografia foram pesados $32 \mathrm{mg}$ de gelatina, diluídos em 4 $\mathrm{ml}$ de água deionizada e esta mistura foi incubada em banho maria $\left(\sim 50^{\circ} \mathrm{C}\right)$ até solubilização total do substrato. Foram acrescentados $1,5 \mathrm{ml}$ dessa solução no preparo do gel. 
Depois de terminada a corrida eletroforética, o gel foi lavado duas vezes durante 15 minutos em solução 2,5\% de Triton X-100 para remoção do SDS, em seguida o gel foi incubado no tampão de hidrólise (Tris- $\mathrm{HCl} 50 \mathrm{mM} \mathrm{pH} \mathrm{8,0} \mathrm{e}$ $\mathrm{CaCl} 25 \mathrm{mM}$ ), a $37^{\circ} \mathrm{C}$ durante 20 horas. Após este tempo o gel foi corado com solução corante Coomassie Blue G-250.

\subsubsection{ATIVIDADE FIBRINOGENOLÍTICA}

O fibrinogênio é uma glicoproteína com massa molecular de $340 \mathrm{kDa}$, formada por seis cadeias polipeptídicas: duas cadeias alfa $(63,5 \mathrm{kDa})$, duas beta (56kDa) e duas gama ( $47 \mathrm{kDa})$, que são interconectadas por pontes dissulfeto e podem ser clivadas pela trombina para formar a rede insolúvel de fibrina na coagulação sanguínea. As enzimas proteolíticas presentes no veneno da serpente são denominadas alfa e/ou beta fibrinogenases. De modo geral, as metaloproteinases de venenos de serpente degradam a cadeia alfa de fibrinogênio e mais lentamente a cadeia beta e as serinoproteinases degradam preferencialmente a cadeia beta do fibrinogênio sem fibrinólise

Para o prepara foram diluídos $4,5 \mathrm{mg}$ de fibrinogênio em $1 \mathrm{~mL}$ de Tris -

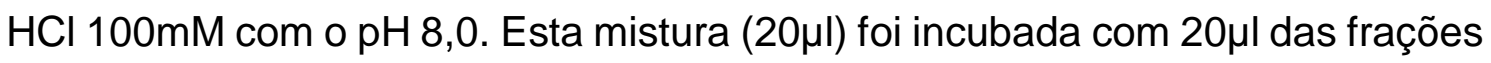
da cromatografia de exclusão molecular. A incubação foi realizada por diferentes tempos (15 min., $30 \mathrm{~min}, 45 \mathrm{~min}, 60 \mathrm{~min}, 90 \mathrm{~min}$ e $120 \mathrm{~min}$.) em estufa a $37^{\circ} \mathrm{C}$. Foi utilizado um controle da amostra sem fibrinogênio e outro apenas com 0 mesmo no tempo de 60 minutos. Após o término da incubação a alíquota foi retirada, e foram adicionados $10 \mu \mathrm{L}$ de tampão de amostra contendo agente redutor e a amostra foi denaturada em banho maria a $75^{\circ} \mathrm{C}$ por 5 minutos para parar a reação. O padrão de degradação do fibrinogênio foi então analisado por SDS-PAGE. 


\subsubsection{ESPECTROMETRIA DE MASSA}

A espectrometria de massas (mass spectrometry) é uma poderosa ferramenta física que caracteriza as moléculas pela medida da relação massa/carga de seus íons. Ela foi usada, inicialmente, na determinação de massas atômicas e, vem sendo empregada na busca de informações sobre a estrutura de compostos orgânicos, na análise de misturas orgânicas complexas, na análise elementar e na determinação da composição isotópica dos elementos. A espectrometria de massas acoplada (MS/MS) é uma técnica analítica poderosa, usada para identificar compostos desconhecidos, quantificar compostos conhecidos e auxiliar na elucidação estrutural de moléculas. A MS/MS tem uma vasta gama de aplicações, como por exemplo: na ecologia, toxicologia, geologia, biotecnologia, e descoberta e desenvolvimento de fármacos.

\subsubsection{SEQUENCIAMENTO DE NOVO AUTOMÁTICO DA FRAÇÃO PEPTÍDICA}

A fração de baixa massa molecular foi congelada em temperatura de $80^{\circ} \mathrm{C}$ e em seguida foi liofilizada. Após a liofilização, a amostra passou por análise de espectrometria de massas ( $\mathrm{MS}^{2}$ e fragmentação por colisão CID) tipo electrospray, as análises foram realizadas em um instrumento IT-TOF (Shimadzu Co., Japan), no Laboratório de Bioquímica e Biofísica do Instituto Butantan. A amostra foi analisada em modo positivo (preferencialmente), após infusão direta no instrumento sob fluxo constante de $20 \mu \mathrm{L} / \mathrm{min}$ em uma solução de $50 \%$ de acetonitrila, contendo $0.5 \%$ de ácido fórmico. O controle do equipamento e aquisição dos dados foram realizados pelo software LCMS Solution e o processamento de dados pelo Mascot. 


\subsubsection{IDENTIFICAÇÃO DE PROTEINAS DAS FRAÇÕES DE ALTA} MASSA DO VENENO

Com o objetivo de identificar as proteases do veneno, frações obtidas pela cromatografia de exclusão molecular de $30 \mathrm{mg}$ de veneno foram submetidas a uma análise de espectrometria de massas em tandem. Cada fração foi liofilizada, ressuspendida em tampão adequado para redução das pontes dissulfeto alquilação das cisteínas e digestão por tripsina. Após a digestão, cada amostra foi analisada por LC-MS/MS e os dados obtidos foram analisados pelos softwares comerciais Peaks e Mascot usando bancos de dados públicos (NCBI e Uniprot). Somente foram considerados resultados significativos.

\subsubsection{PADRONIZAÇÃO DE UM MÉTODO FLUORIMÉTRICO PARA DETECÇÃO E QUANTIFICAÇÃO DE ATIVIDADE CASEINOLÍTICA}

Para fins de "screening" das frações com atividade caseinolítica, padronizamos o ensaio descrito abaixo. Tal opção se deu pelo fato de dispormos de um leitor de fluorescência para microplacas, possibilitando assim a análise simultânea de até 96 amostras, e também, pelo fato de ensaios usando fluoróforos se mostrarem mais sensíveis que aqueles baseados em absorvância. Para este ensaio utilizou-se como substrato caseína conjugada com FITC (Fluorescein Isothiocyanate) Este substrato é clivado pelas proteases presentes no veneno de serpentes, e o sobrenadante contendo os peptídeos fluorescentes, após precipitação das proteínas com ácido tricloroacético (TCA) e ajuste de $\mathrm{pH}$, pode ser analisado em fluorímetro.

Para o preparo do substrato foram utilizados $200 \mathrm{mg}$ de caseína, diluídas em $20 \mathrm{~mL}$ de tampão ( $50 \mathrm{mM}$ de carbonato de sódio, $150 \mathrm{mM}$ de $\mathrm{NaCl}$, pH 9,5). A mistura foi incubada com $8 \mathrm{mg}$ de FITC por 8 horas. A reação foi dialisada a $4^{\circ} \mathrm{C}$

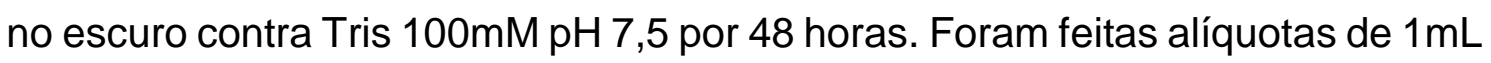
que foram congeladas até o momento de sua utilização. 
O reagente de trabalho foi feito da seguinte maneira: $5 \mu \mathrm{L}$ de FITC caseína

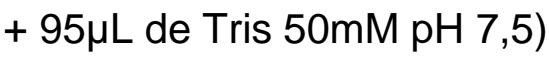

Utilizamos $5 \mu \mathrm{L}$ de cada fração do veneno da Pseudechis australis e fizemos uma diluição em $40 \mu \mathrm{L}$ de tampão Tris e $5 \mu \mathrm{L}$ da solução de caseína, com intervalos de 1 minuto para cada tubo. Os tubos foram incubados por 20 minutos a $37^{\circ} \mathrm{C}$. Adicionamos $120 \mu \mathrm{L}$ de TCA $5 \%$ (Com intervalos de 1 minuto para cada tubo). A mistura foi deixada por 10 minutos no gelo e centrifugada a $10000 \mathrm{G}$ por 10 minutos. Transferiu-se $90 \mu \mathrm{L}$ do sobrenadante para a placa de 96 poços e adicionamos $90 \mu \mathrm{l}$ de Tris $50 \mathrm{mM} \mathrm{pH} \mathrm{8,5}$ para ajustar o $\mathrm{pH}$ para a leitura. A leitura foi realizada em fluorímetro de placas da marca Thermo Scientific, modelo Fluoroskan Ascent com $\lambda e x=490 \mathrm{~nm}$ e $\lambda e m=522 \mathrm{~nm}$. Para o branco utilizamos $5 \mu \mathrm{L}$ de tampão no lugar do veneno.

\subsubsection{SEQUENCIAMENTO DE NOVO DE PEPTÍDEOS NATURAIS DO} VENENO DE Pseudechis australis.

As frações de baixa massa resultantes da gel filtração foram coletadas e liofilizadas para análise de espectrometria de massas on-line com cromatografia líquida de fase reversa (LC-ESI-IT-MS/MS - Shimadzu). As amostras foram ressuspendidas em $50 \mu \mathrm{L}$ de solução $A(0,05 \%$ de ácido acético) e pipetadas na placa de injeção automatizada do sistema. A cromatografia de fase reversa separa os componentes da amostra por gradiente, com solução B ( $A C N+10 \%$ de A), que foram constantemente injetados no espectrômetro de massas em um fluxo de $50 \mu \mathrm{L} / \mathrm{min}$. Os peptídeos foram ionizados por eletrospray e analisados em MS/MS. Cada tempo de retenção da cromatografia gerou um espectro de íons em $\mathrm{MS}^{1}$ e os íons pais com maior intensidade foram automaticamente selecionados, fragmentados por colisão CID e os íons filhos resultantes foram reanalisados em $\mathrm{MS}^{2}$. O conjunto de informações obtidas de $\mathrm{m} / \mathrm{z}$ de cada íon em $\mathrm{MS}^{1}+\mathrm{MS}^{2}$ de cada amostra analisada foi compilado em arquivos de extensão .mgf, utilizados no software PEAKS. O parâmetro "erro de detecção de massa" foi regulado em $0,05 \mathrm{kDa}$ e o algoritmo de sequenciamento de novo automático gerou para cada amostra uma lista de possíveis candidatos. Os resultados de interesse foram confirmados avaliando manualmente a qualidade dos espectros. 


\section{RESULTADOS}

\subsection{CROMATOGRAFIA DE EXCLUSÃO MOLECULAR DO VENENO TOTAL DE Pseudechis australis.}

Os componentes da amostra do veneno foram separados por tamanho, resultando em três picos (figura 2) que foram agrupados e posteriormente foram submetidos ao ensaio eletroforético.

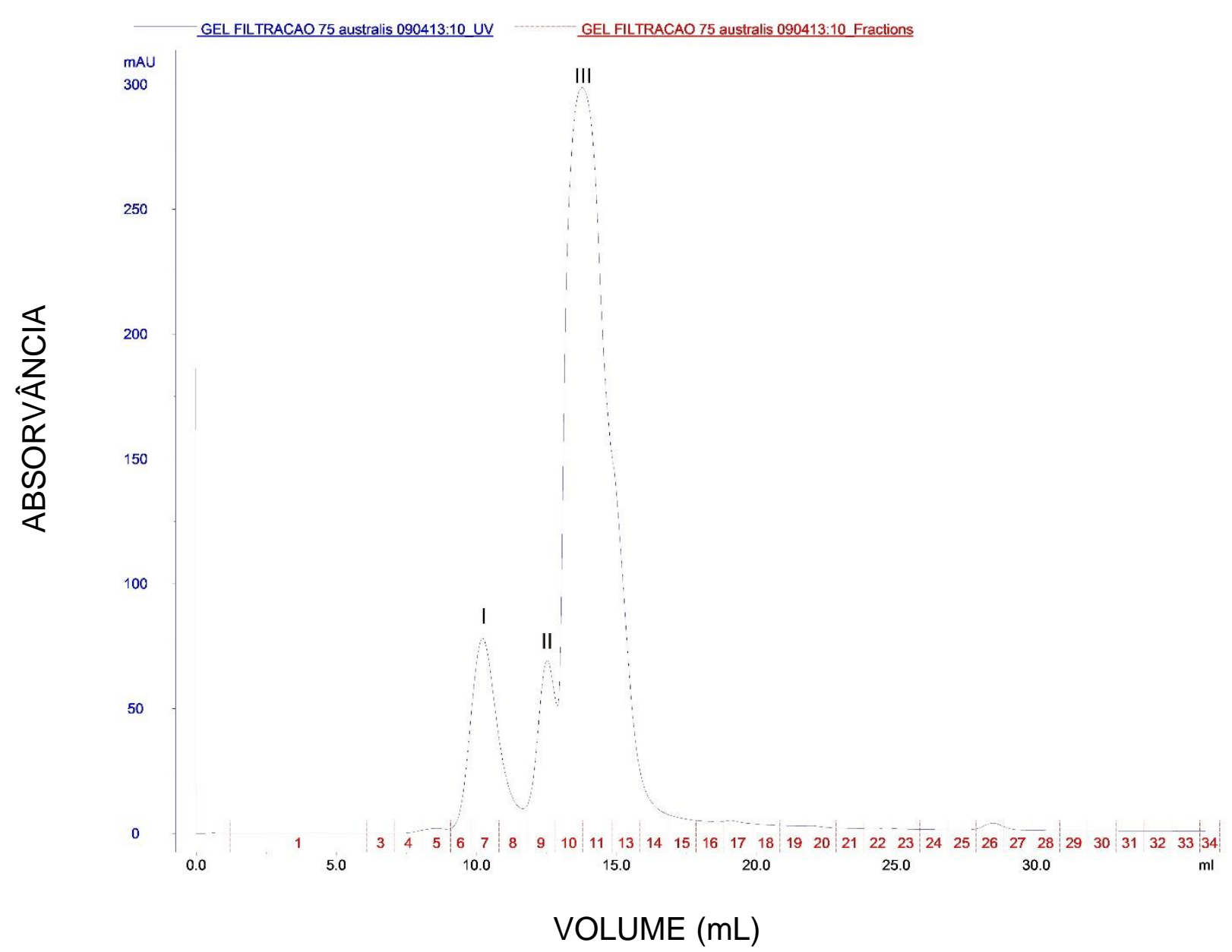

Figura 2 - Cromatografia de exclusão molecular do veneno de Pseudechis australis. O veneno retido na membrana Centricon $®$ foi diluído em $1,2 \mathrm{~mL}$ em bicarbonato de amônio $100 \mathrm{mM}$. Injetado $1 \mathrm{~mL}$ da amostra em uma coluna Superdex 75 10/300GL, com um fluxo de $0,5 \mathrm{ml} /$ minuto. 


\subsection{ELETROFORESE GEL SDS-PAGE 15\%}

Os picos da cromatografia de exclusão molecular acima foram analisados por SDS-PAGE (figura 3). Eletroforese realizada com os 3 picos coletados da cromatografia de exclusão molecular. Os picos coletados foram utilizados com (R) e sem um agente redutor (NR). Os picos 1 e 2 apresentaram bandas de aproximadamente 60 a $45 \mathrm{kDa}$ e no pico foram observadas bandas por volta de $14 \mathrm{kDa}$.

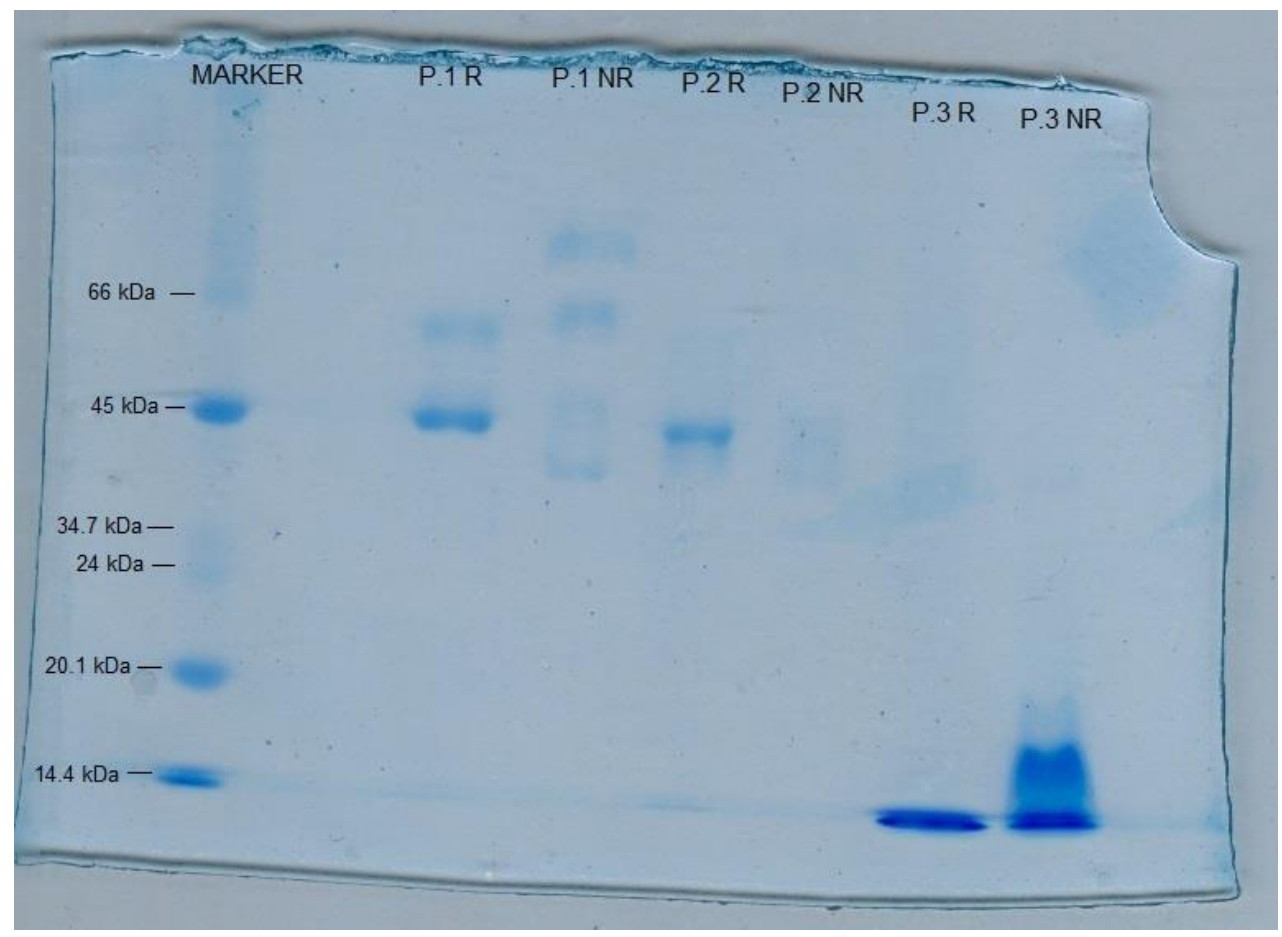

Figura 3 - Eletroforese realizada com os 3 picos coletados da cromatografia de exclusão molecular. Os picos coletados foram utilizados com (R) e sem um agente redutor (NR). Os picos 1e 2 apresentaram bandas de aproximadamente 60 a $45 \mathrm{kDa}$ e no pico foram observadas bandas por volta de $14 \mathrm{kDa}$.

A análise indica a existência de bandas existem duas bandas de massa similar nos picos 1 e 2 . Todavia, na ausência de agente redutor, o pico 1 apresenta bandas de maior massa $(\sim 75 \mathrm{kDa})$ que não são visualizadas na presença de redutor, sugerindo a presença de moléculas multiméricas. 


\subsection{ATIVIDADE CASEINOLÍTICA}

No ensaio de atividade proteolítica usando substrato fluorescente (figura 4), observamos que o pico dois da cromatografia de exclusão molecular do veneno da Pseudechis australis apresentou alta atividade hidrolítica, superior ao veneno de $B$. Jararaca (controle positivo) que sabidamente apresenta intensa atividade caseinolítica.

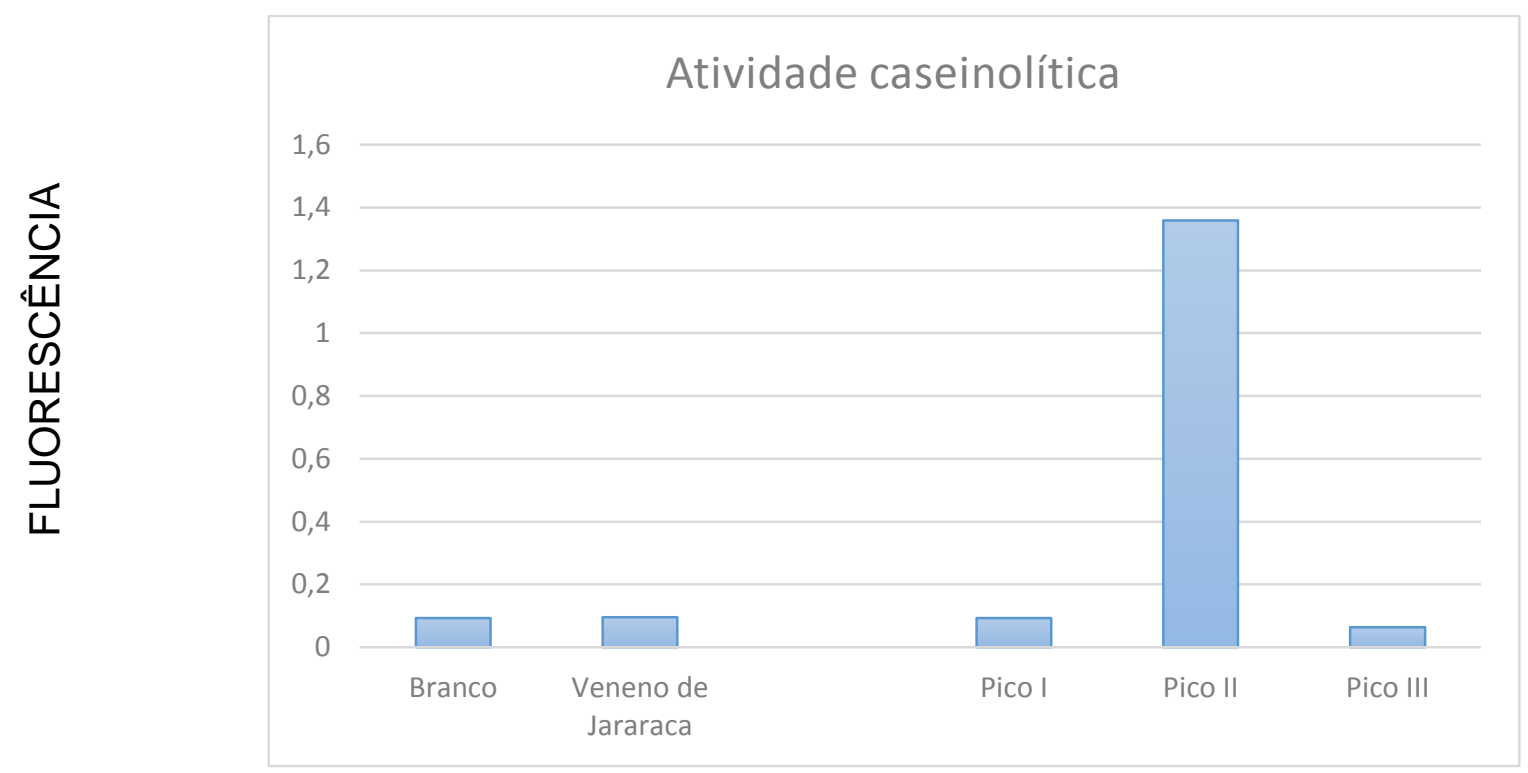

\section{AMOSTRA}

Figura 4 - Ensaio de atividade caseinolítica utilizando as amostras da cromatografia de exclusão molecular do veneno da Pseudechis australis e utilizando como controle o veneno de Bothrops jararaca. A amostra do pico II foi o que apresentou maior atividade ao medir sua fluorescência comparado aos outros picos.

\subsection{ZIMOGRAFIA COM AGENTES INIBIDORES}

Foi realizada uma zimografia (figura 5) usando gelatina como substrato com os picos da exclusão molecular na ausência de inibidores de protease visando identificar as frações ativas. Observamos atividade gelatinolítica no pico dois mostrando clivagem da gelatina em duas regiões distintas do gel indicando a presença de pelo menos 2 bandas com atividade gelatinolítica e confirmando o ensaio com fluoróforo. 


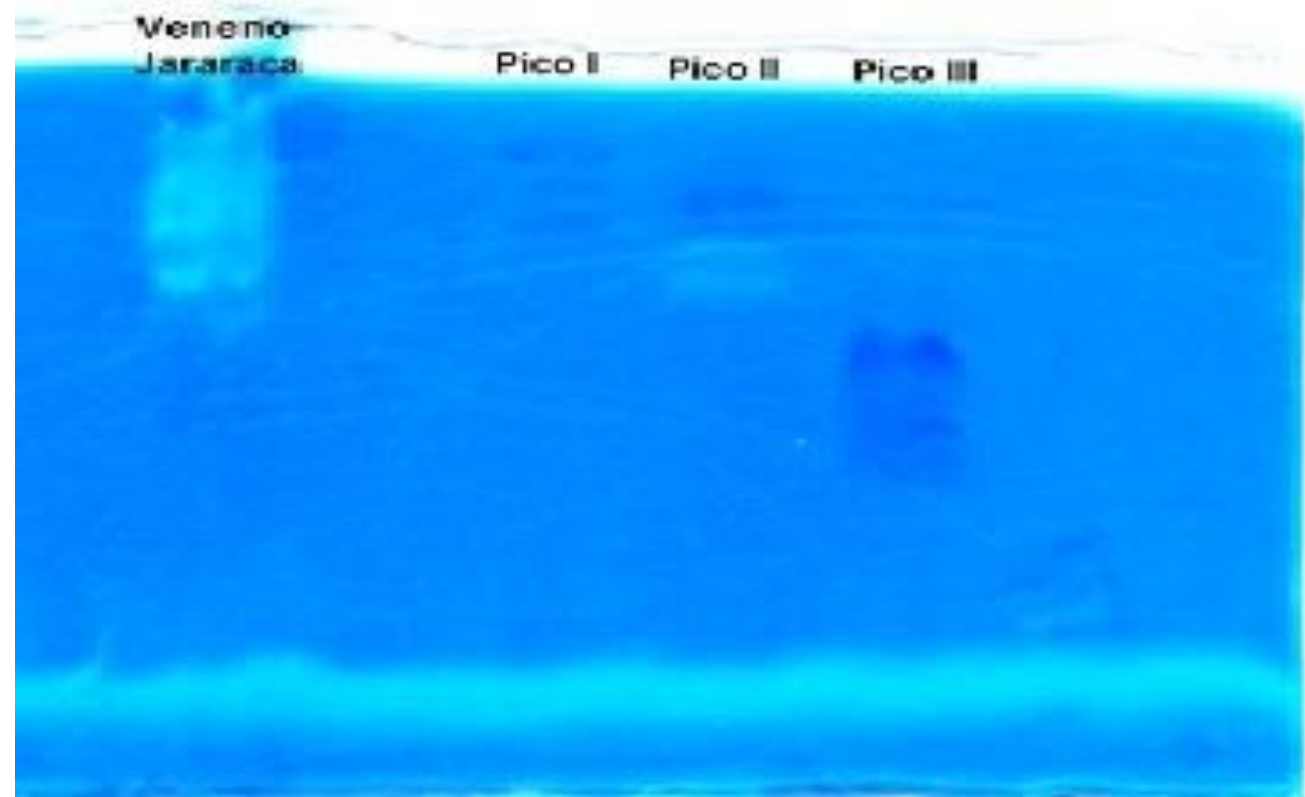

Figura 5 - Ensaio de zimografia utilizando os 3 picos coletados da cromatografia de exclusão molecular e utilizando veneno de Bothrops jararaca como controle. Observamos que apenas o pico 2 teve atividade gelatinolítica, gerando duas bandas em regiões distintas do gel.

Após este primeiro ensaio de zimografia e com os dados obtidos pelo ensaio de atividade caseinolítica, foi realizado outro ensaio zimográfico (figura 6) só que desta vez, após incubação com um inibidor de metaloproteases (EDTA).

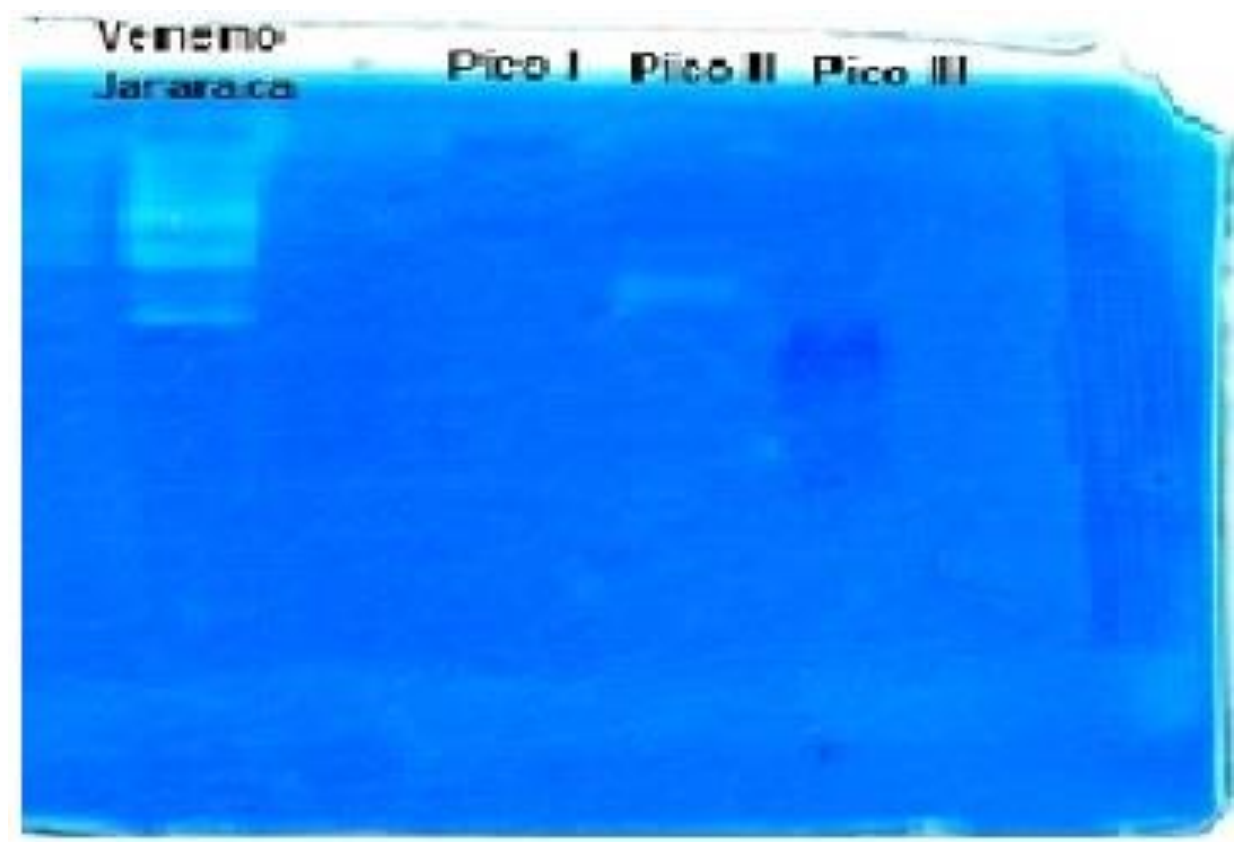

Figura 6 - Ensaio de zimografia utilizando os 3 picos coletados de cromatografia de exclusão molecular, na presença de um inibidor de metaloproteases (EDTA). Nota-se que este agente inibe uma das bandas do pico 2. 
Observamos que o quelante inibiu a atividade hidrolítica de uma das bandas do pico 2, evidenciando que a enzima depende de cátions divalentes para desempenhar sua função, o que sugere fortemente que seja uma metaloprotease, ao passo que aquela cuja atividade foi preservada muito provavelmente pertence à classe das serinoproteases.

O ensaio foi repetido mais uma vez, utilizando apenas o pico onde houve atividade gelatinolítica, utilizando a amostra com e sem inibidor de metaloprotease (figura 7).

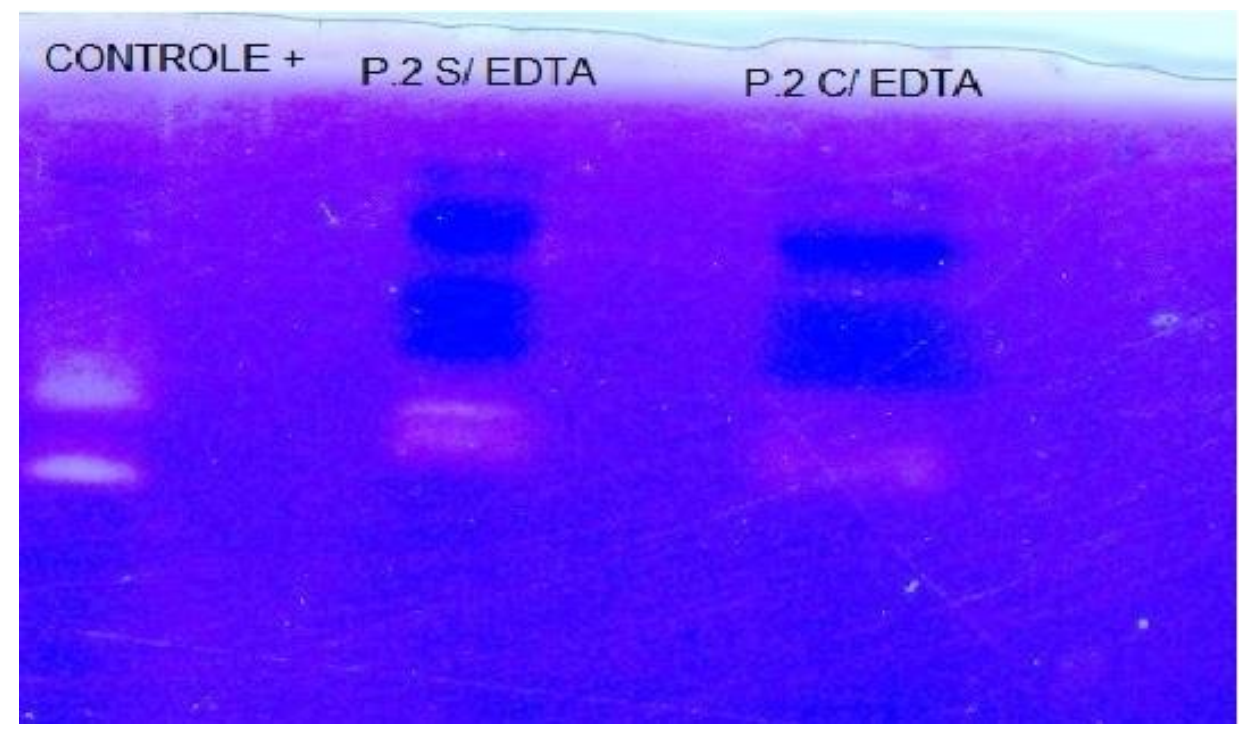

Figura 7 - Novo ensaio de zimografia utilizando apenas o pico 2 coletado da cromatografia de exclusão molecular, utilizando amostra sem agente inibidor e com agente inibidor, mostrando claramente que o agente inibiu uma das bandas geradas no gel.

Observando a figura 7, temos duas amostras do pico dois, a primeira sem o agente inibidor e a segunda com o quelante. Mais uma vez, apenas uma banda é inibida indicando ser uma metaloprotease.

Como a outra banda não foi inibida foi realizado mais um ensaio zimográfico (figura 8) utilizando outro agente inibidor que neste caso inibe serinoprotease (PMSF). 


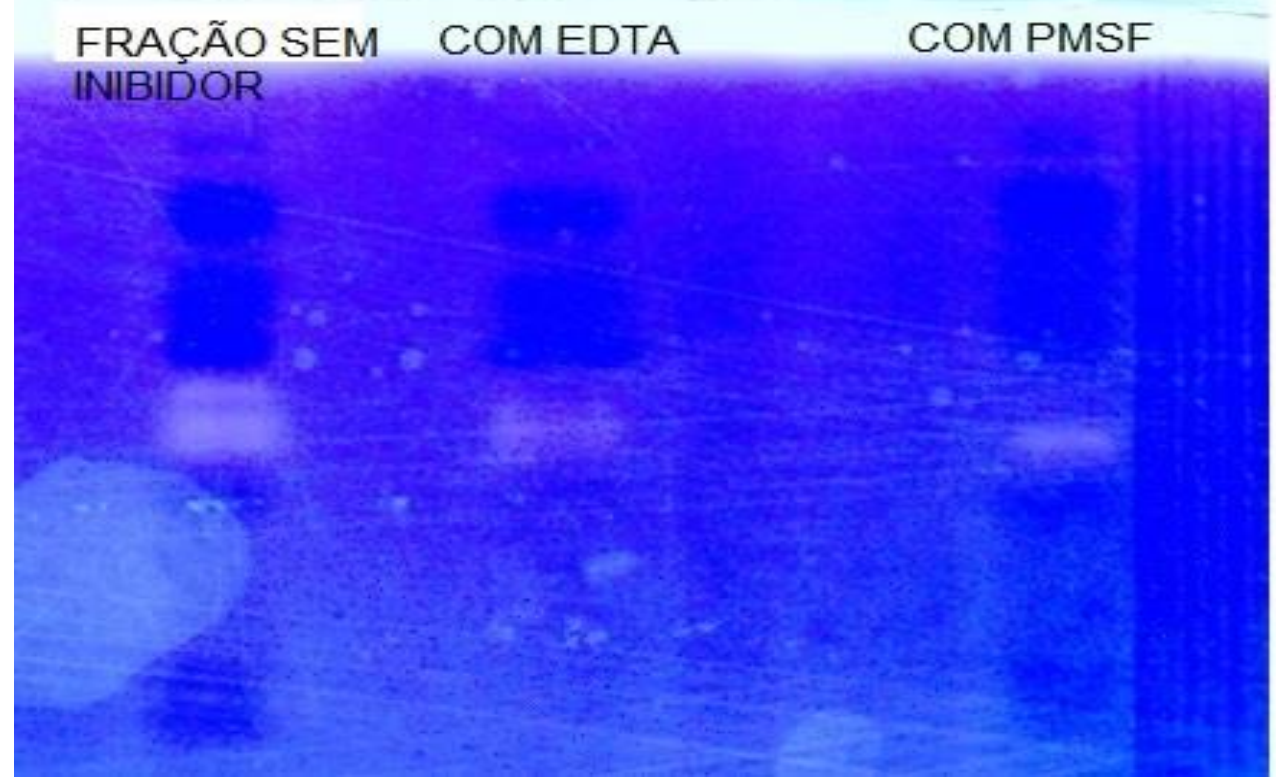

Figura 8 - Um novo ensaio de zimografia foi realizado com o pico 2 coletado da cromatografia de exclusão molecular, dessa vez utilizando um agente inibidor de metaloproteases (EDTA) e um agente inibidor de serinoproteases (PMSF), mostrando que cada agente inibiu uma banda distinta, indicando que uma banda é uma metaloprotease e a outra uma serinoprotease.

Utilizando inibidores específicos tanto de metaloproteases quanto de serinoproteases, vemos que a fração correspondente ao pico 2 contém uma protease de cada classe.

\subsection{ATIVIDADE FIBRINOGENOLÍTICA}

Depois da realização da zimografia utilizando inibidores específicos, fizemos um ensaio utilizando fibrinogênio (figura 9) para averiguar se a enzima tinha atividade sobre este substrato. 


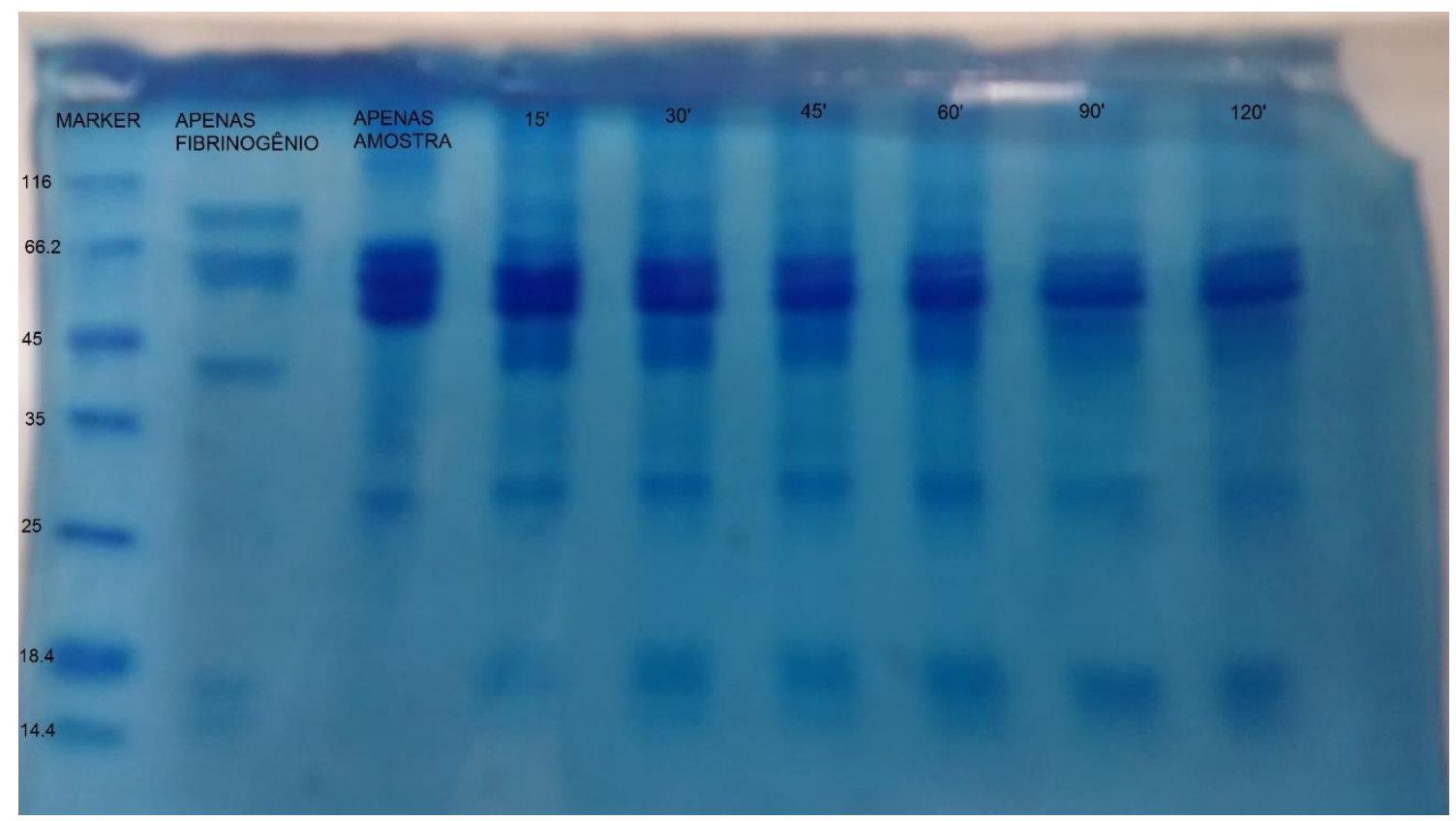

Figura 9 - Ensaio de atividade fibrinogenolítica do pico que apresentou atividade proteolítica. Como controles foram usados uma amostra contendo apenas o fibrinogênio e outra contendo apenas o pico 2. O ensaio foi realizado em diversos tempo entre 15 minutos até 120 minutos. Houve clivagem da primeira cadeia que é a alfa sugerindo que a amostra injetada contem metaloproteases.

Podemos observar que em todos os tempos, a cadeia alfa foi clivada sugerindo, dada a maior especificidade destas enzimas pela cadeia alfa, que a amostra contém metaloproteases, confirmando os resultados acima.

Um ensaio de fibrinogênio foi realizado, utilizando inibidores de serinoproteases (figura 10). 


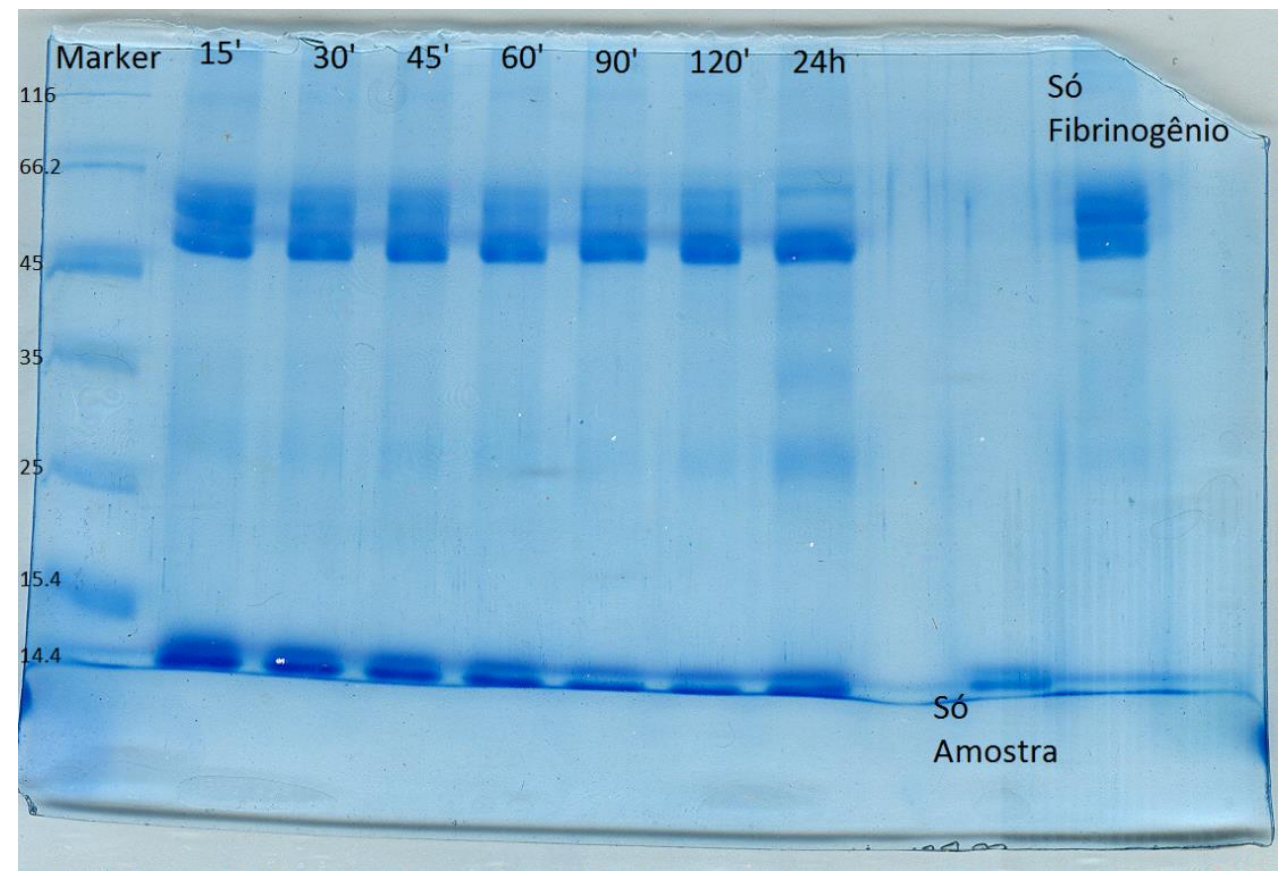

Figura 10 Ensaio de atividade fibrinogenolítica do pico 2 coletado da cromatografia. Como controle foram usados uma amostra contendo apenas o pico 2 e a outra contendo apenas 0 fibrinogênio. $O$ ensaio foi realizado em diversos tempos entre 15 minutos ate 24 horas. Houve clivagem da segunda cadeia que é beta, sugerindo que a amostra injetada contem serinoprotease

Podemos observar na figura 10 que no tempo de 24 horas, a cadeia beta foi clivada sugerindo, dada a maior especificidade destas enzimas pela cadeia beta, que a amostra contém serinoprotease 


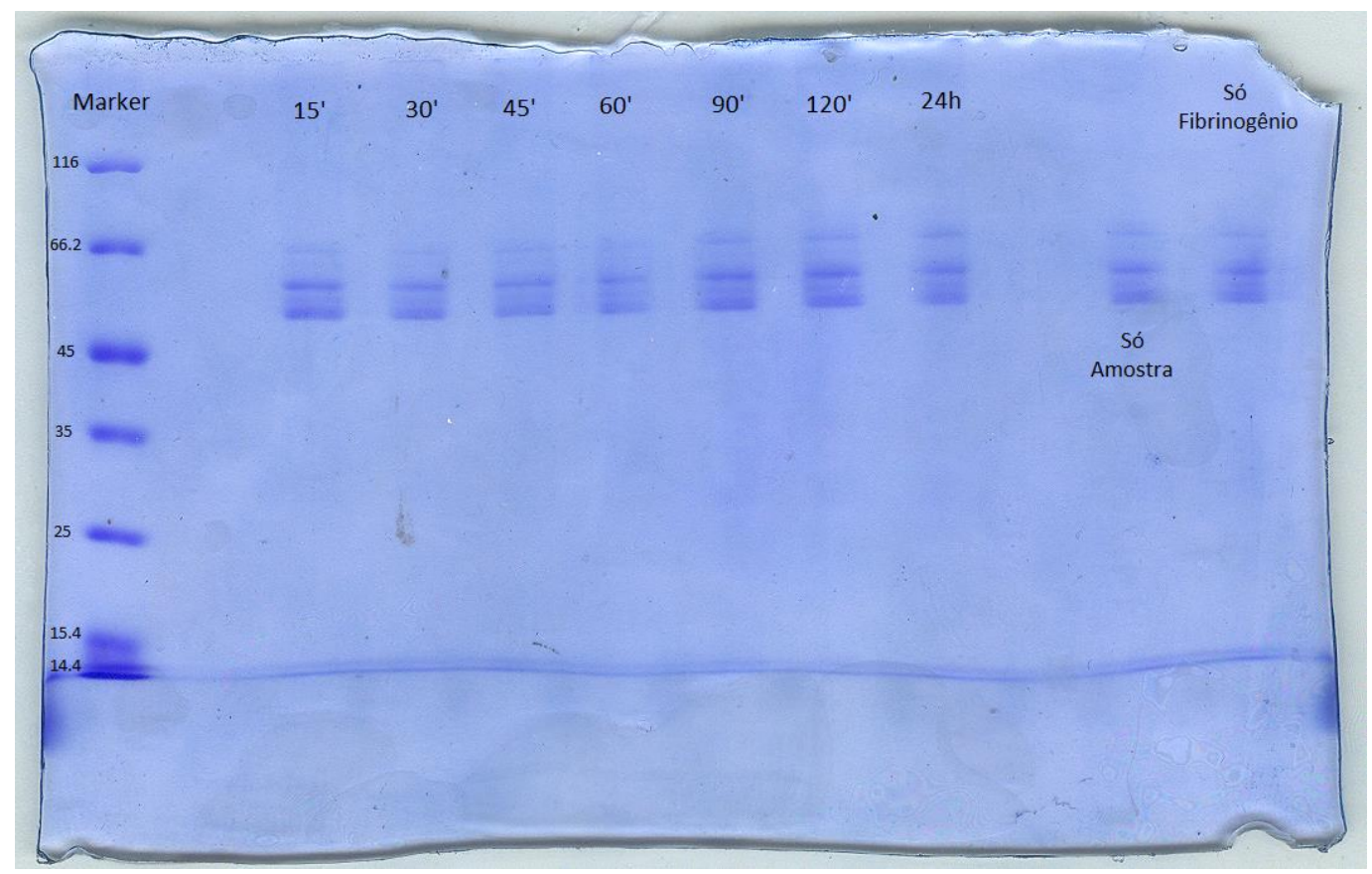

Figura 11 Ensaio de atividade fibrinogenolítica do pico 2 coletado da cromatografia, usando um inibidor de serinoprotease. Como controle foram usados uma amostra contendo apenas o pico 2 e a outra contendo apenas o fibrinogênio. O ensaio foi realizado em diversos tempos entre 15 minutos até 24 horas. Não houve clivagem da cadeia beta, comprovando que a serinoprotease que a amostra contém foi inibida

Observando a figura 11, notamos que em todos os tempos, não houve clivagem de nenhuma cadeia, comprovando que a amostra contém serinoprotease. 
4.6 ESPECTROMETRIA DE MASSA E CROMATOGRAFIA DE EXCLUSÃO DO VENENO DA Pseudechis australis

\subsubsection{SEQUENCIAMENTO DE NOVO DE PEPTIDEOS NATURAIS DO VENENO DE Pseudechis australis}

O PEAKS gerou uma lista de peptídeos com bom score na fração 5-1 (TAB. 1).

TABELA 1. Peptídeos sequenciados de novo automaticamente pelo PEAKS com os espectros de massas dos peptídeos naturais da fração 5-1 da gel filtração do veneno total de Pseudechis australis analisados por LC-ESI-IT-MS/MS. O íon

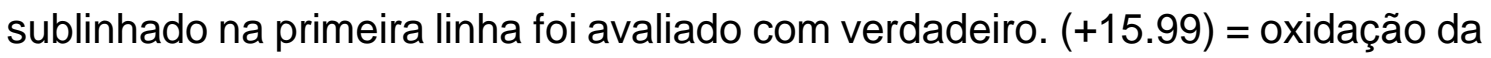
metionina; $\mathrm{ALC}=$ score total de confiança do sequenciamento; $\mathrm{m}=$ massa; $\mathrm{z}=$ carga; massa em Da.

\begin{tabular}{cccccc}
\hline Peptídeo & ALC (\%) & $\mathbf{m} / \mathbf{z}$ & $\mathbf{z}$ & Massa & \% confiança local \\
\hline$\underline{\text { EQQQ }}$ & $\underline{87}$ & $\underline{266.6297}$ & $\underline{2}$ & $\underline{531.2289}$ & $\underline{91} \underline{85} \underline{79} \underline{95}$ \\
${ } }$ & 86 & 532.1906 & 1 & 531.2111 & 89779487 \\
M(+15.99)ETH & 75 & 267.097 & 2 & 532.1951 & 73667983 \\
FETH & 74 & 267.097 & 2 & 532.2281 & 72647883 \\
ETFH & 66 & 267.097 & 2 & 532.2281 & 72814372 \\
\hline
\end{tabular}

Dentre estes peptídeos, o primeiro da lista EQQQ $(\mathrm{m} / \mathrm{z}=266.6297 ; \mathrm{z}=2)$ foi avaliado e identificado como verdadeiro. Ele teve o maior score total $(A L C=$ $87 \%$ ) e todos os seus resíduos tiveram score de confiança local superior a $75 \%$. O seu espectro de massas da fragmentação, o alinhamento dos íons filhos e a tabela de massas dos íons de sua série de fragmentação estão apresentados na figura 12. 


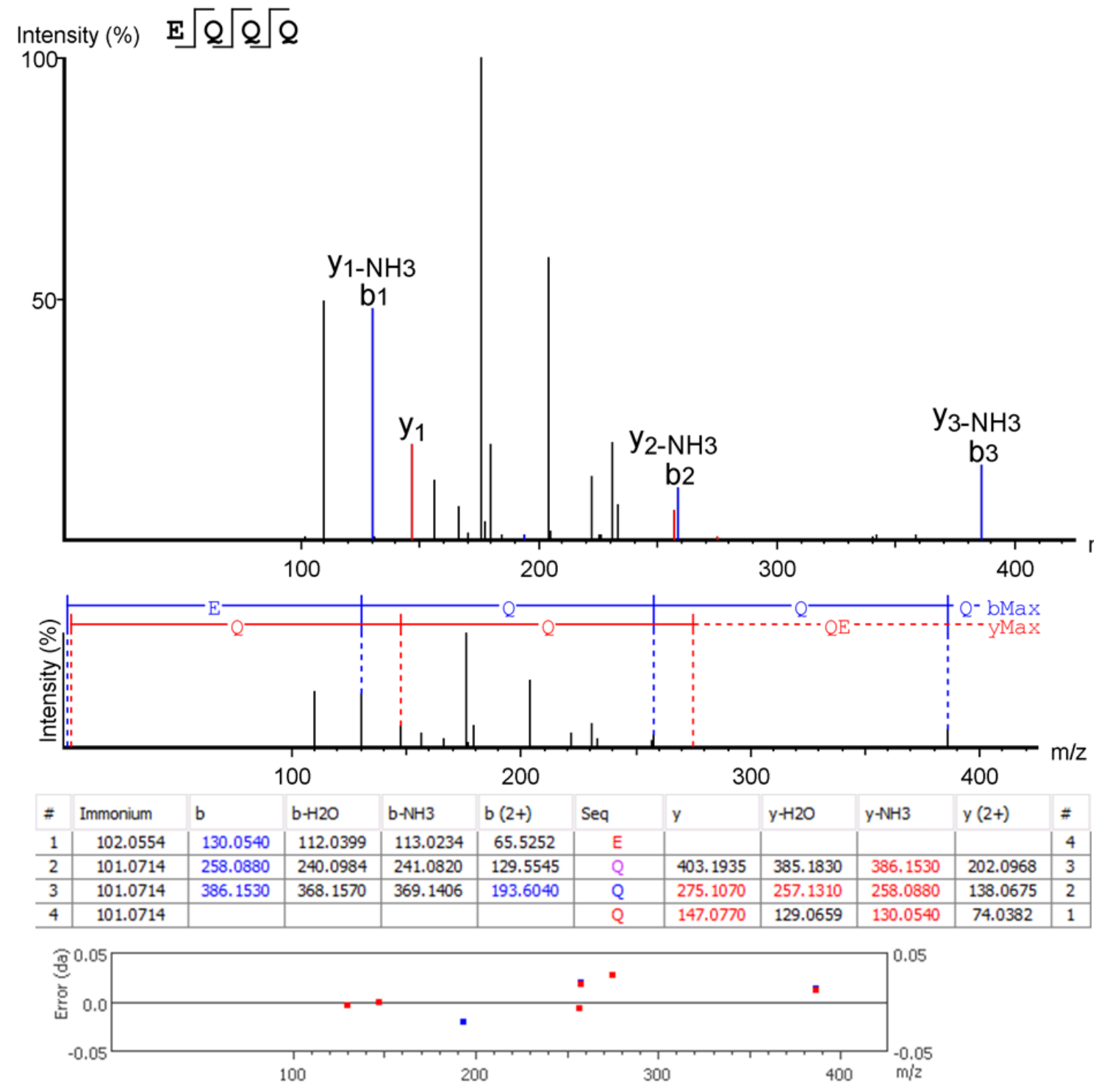

Figura 12 Espectro de massas da fragmentação do íon pai ( $\mathrm{m} / \mathrm{z}=266.6297)$, sequenciado automaticamente pelo PEAKS como EQQQ e confirmado manualmente. O espectro de fragmentação, o alinhamento da sequencia no espectro, a tabela de massas das séries de fragmentação dos íons filhos e o erro de detecção de massa, confirmam o sequenciamento.

A sequência EQQQ foi alinhada por BLAST com banco de dados de proteínas público $(\mathrm{NCBI})$, restringido ao grupo Squamata. Este peptídeo está presente na porção pro-peptídeo de um peptídeo natriurético prematuro de veneno de Oxyuranus scutellatus scutellatus (UniProtKB/Swiss-Prot accession: P83228), do aminoácido no 48 ao nํㅜ 51. 


\subsubsection{IDENTIFICAÇÃO DE PROTEINAS DAS FRAÇÕES DE ALTA MASSA DO VENENO}

A cromatografia de exclusão molecular com $30 \mathrm{mg}$ de veneno gerou seis frações, que posteriormente foram liofilizadas e analisadas por espectrometria de massas

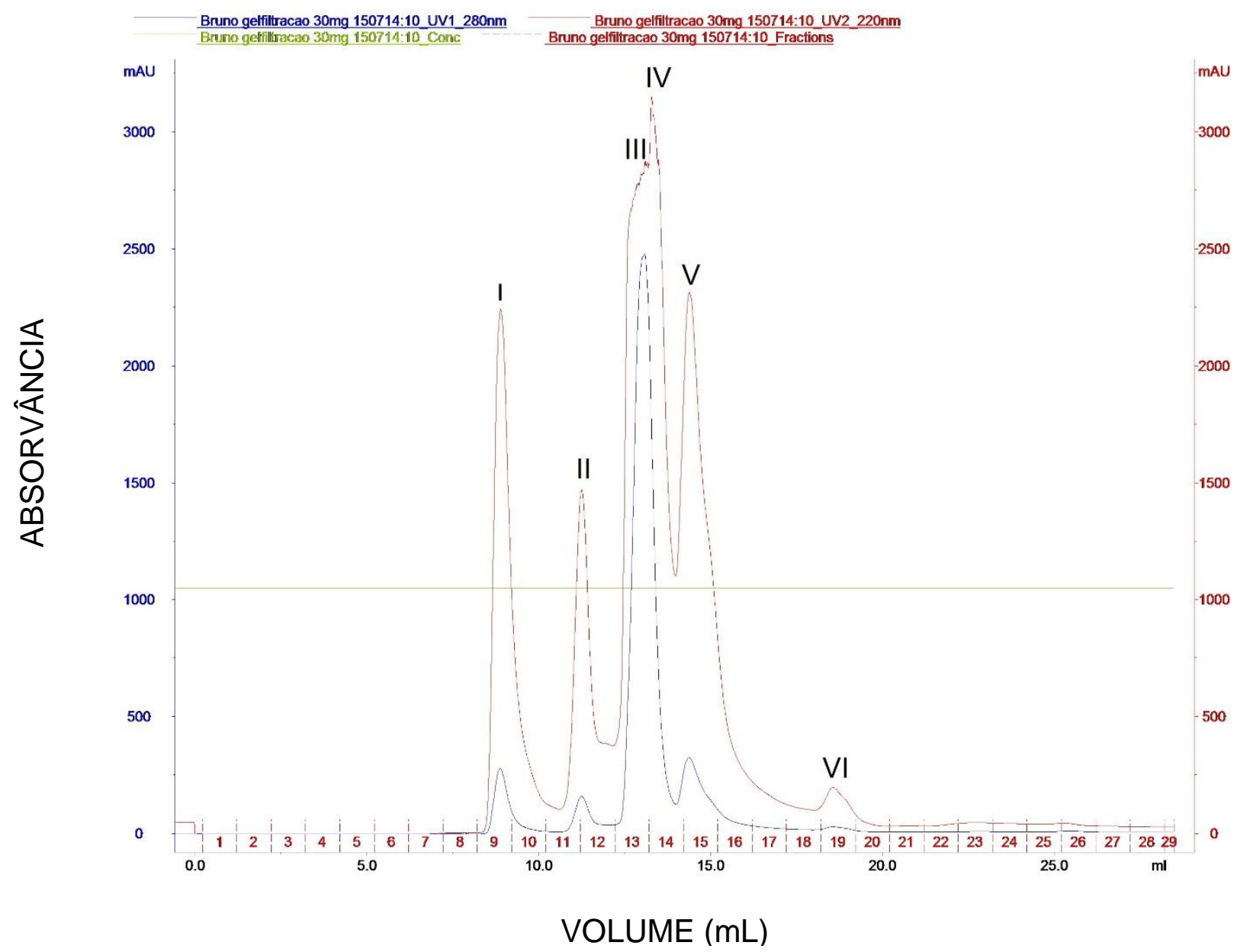

Figura 13 - Cromatografia de exclusão molecular de $30 \mathrm{mg}$ de veneno de Pseudechis australis, diluído em $1,2 \mathrm{~mL}$ no tampão de amostra de bicarbonato de amônio $100 \mathrm{mM}$, em coluna Superdex 75 10/300GL, com um fluxo de 0,5ml/minuto. A absorvância do eluato foi monitorada em $220 \mathrm{e}$ $280 \mathrm{~nm}$.

Foram identificadas proteínas somente em três das seis frações. A tabela 2 mostra que nos picos III, IV e V foram identificadas isoformas de PLA2, porém nenhuma protease pôde ser detectada. Sabidamente, os venenos elapídicos contém grandes quantidades de neurotoxinas, dentre elas as fosfolipases. Este fato pode fazer com que sinais de menor intensidade tenham sido mascarados durante a análise por espectrometria de massa, um vez que o instrumento tende a selecionar os íons de maior sinal, dificultando a identificação de fragmentos peptídicos menos abundantes. 
TABELA 2: Identificação com PEAKS de proteínas nas frações de exclusão molecular do veneno de Pseudechis australis por espectrometria de massas LC-MS/MS de peptídeos trípticos. Fração: número da fração utilizada; Accession: Codigo dos hits; Cov: porcentagem de cobertura na proteína; Peptides: quantidade de peptídeos gerados; Avg Mass: massa media; m/z: massa sobre carga em Da; Score: pontuação de veracidade: [P]EAKS:Score do PEAKS; [M]ascot: Score do Mascot.

\begin{tabular}{|c|c|c|c|c|c|c|c|c|c|c|c|c|}
\hline Fração & Accession & $\begin{array}{c}\text { Score } \\
(\%)\end{array}$ & $\begin{array}{c}\text { Coverage } \\
(\%)\end{array}$ & Peptides & $\begin{array}{l}\text { Avg. } \\
\text { Mass }\end{array}$ & Descrição & Peptideo & $\mathrm{m} / \mathrm{z}$ & Mass & Score (\%) & {$[P] E A K S$} & [M] ascot \\
\hline & $\begin{array}{c}\operatorname{tr}|Q 45 Z 18| \\
\text { Q45Z18_P } \\
\text { SEAU }\end{array}$ & 98,81 & 30 & 6 & 15939 & $\begin{array}{c}\text { Phospholipase } \\
\text { Pa-20 } \\
\text { OS=Pseudechis } \\
\text { australis } P E=2 \\
\text { SV }=1\end{array}$ & $\begin{array}{c}\text { K.RIVC }(+5 \\
7.02) \text { DC }(+5 \\
7.02) \text { DAAV } \\
\text { AK.C }\end{array}$ & $\begin{array}{c}689,327 \\
1\end{array}$ & $\begin{array}{r}1376 \\
, 654\end{array}$ & 99,95 & 48,42 & 66,05 \\
\hline & & & & & & & $\begin{array}{l}\text { K.C(+57.02) } \\
\text { FAKAPYKKE } \\
\text { NYNIDTK.T }\end{array}$ & $\begin{array}{c}697,342 \\
9\end{array}$ & $\begin{array}{c}2089 \\
, 03\end{array}$ & 99,95 & 52,82 & 40,93 \\
\hline \multirow[t]{3}{*}{ III } & & & & & & & $\begin{array}{l}\text { L.NLIQLSN } \\
\text { MIK.C }\end{array}$ & $\begin{array}{c}587,334 \\
7\end{array}$ & $\begin{array}{c}1172 \\
66\end{array}$ & 99,95 & 40,11 & 54,59 \\
\hline & & & & & & & $\begin{array}{l}\text { K.C }(+57.02) \\
\text { KRIVC }(+57 . \\
\text { 02)DC }(+57 . \\
\text { 02)DAAVAK } \\
. C\end{array}$ & 555,935 & $\begin{array}{c}1664 \\
, 78\end{array}$ & 99,95 & 38,12 & 39,59 \\
\hline & & & & & & & $\begin{array}{c}\text { K.APYKKEN } \\
\text { YNIDTKTR. } \\
\text { C }\end{array}$ & 614,319 & $\begin{array}{c}1839 \\
, 95\end{array}$ & 99,92 & 27,81 & 34,86 \\
\hline
\end{tabular}




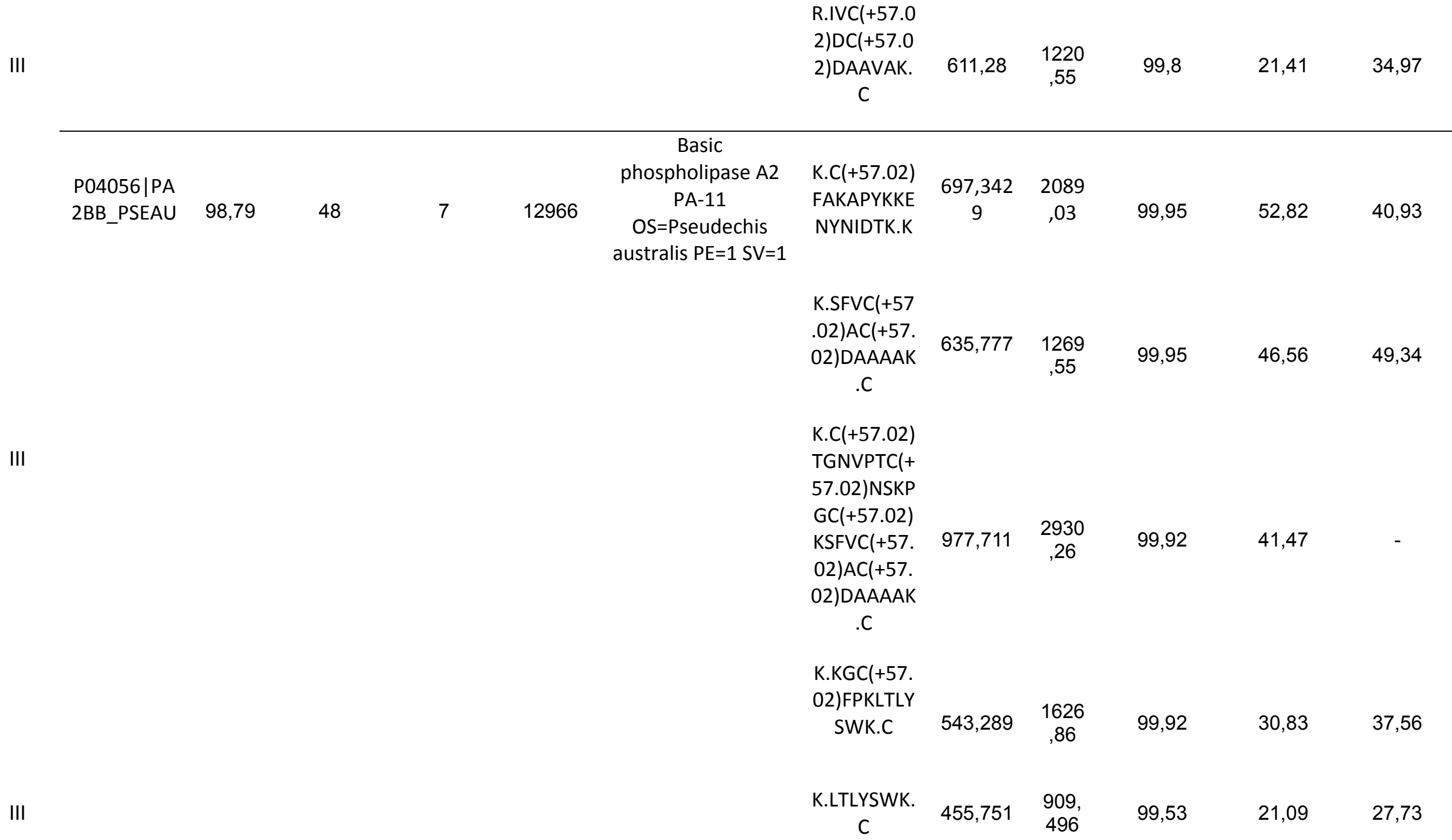


III

Y.SWKC +5

7.02)TGNV

PTC $(+57.02$

)NSKPGCl+

$694,306 \quad 2079$

95,59

27,27

57.02)K.S

K.LTLYSWK

$\mathrm{C}(+57.02) \mathrm{T}$

GNVPTC $(+5$

7.02)NSKP

$857,75 \quad 2470$

$\mathrm{GC}(+57.02)$

K.S

$\operatorname{tr|Q45Z21|}$
Q45Z21_PS
EAU

\section{Phospholipase A2}

$$
\text { Pa-18 }
$$

OS=Pseudechis

australis $\mathrm{PE}=2 \mathrm{SV}=1$

L.NLIQFGN

MIQC(+57.

02)ANKGSR

PTR.H

769,062

2304

PTR.H

K.AAYNDA

NWNIDTK.T $\quad 748,345 \quad 1494$

99,93

29,23

54,2

$\begin{array}{ccccc}\operatorname{tr} \mid \text { Q45Z16 } \mid & & & & \\ \begin{array}{c}\text { Q45Z16_PS } \\ \text { EPO }\end{array} & 83,64 & 23 & 3 & 15930\end{array}$

Phospholipase $\mathrm{A} 2$
OS=Pseudechis
porphyriacus $\mathrm{PE}=2$

L.NLIQFGN

MIQC(+57.

III

EPO

$\mathrm{SV}=1$

02)ANKGSR

PTR.H

769,062

2304

,16

99,95

22,5

58,27

K.KGCl+57.

\begin{tabular}{|c|c|c|c|c|}
\hline 02)FPKLTLY & 543,289 & $\begin{array}{r}1626 \\
86\end{array}$ & 99,5 & 30,83 \\
\hline
\end{tabular}




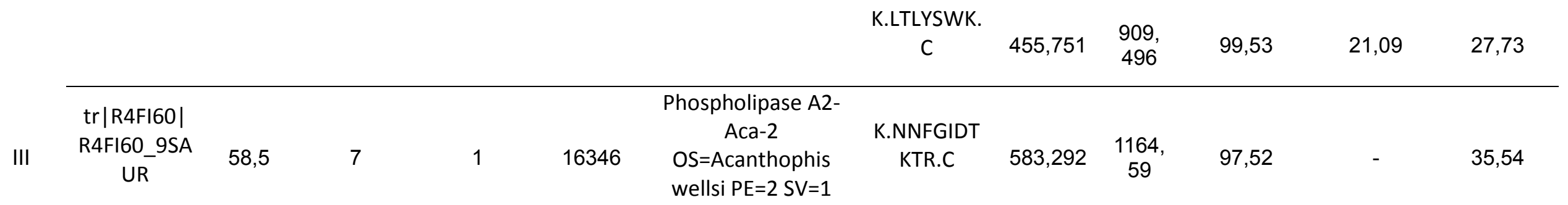




\begin{tabular}{|c|c|c|c|c|c|c|c|c|c|c|c|c|}
\hline Fração & Accession & $\begin{array}{c}\text { Score } \\
(\%)\end{array}$ & $\begin{array}{c}\text { Coverage } \\
(\%)\end{array}$ & Peptides & $\begin{array}{l}\text { Avg. } \\
\text { Mass }\end{array}$ & Descrição & Peptideo & $\mathrm{m} / \mathrm{z}$ & Mass & $\begin{array}{c}\text { Score } \\
(\%)\end{array}$ & [P]EAKS & [M] ascot \\
\hline \multirow{2}{*}{ IV } & $\begin{array}{c}\text { P04057|PA2 } \\
\text { BD_PSEAU }\end{array}$ & 89,17 & 23 & 4 & 13213 & $\begin{array}{c}\text { Basic phospholipase } \\
\text { A2 PA-13 } \\
\text { OS=Pseudechis } \\
\text { australis } \mathrm{PE}=1 \mathrm{SV}=1\end{array}$ & $\begin{array}{l}\text { K.C }(+57.02) K \\
\text { DFVC }(+57.0 \\
\text { 2)AC }(+57.02 \\
\text { )DAAAAK.C }\end{array}$ & 793,837 & $\begin{array}{c}1585 \\
67\end{array}$ & 99,93 & 54,98 & 61,09 \\
\hline & & & & & & & $\begin{array}{c}\text { K.MIQC(+57. } \\
\text { 02)ANKGSR. } \\
\text { A }\end{array}$ & 582,775 & $\begin{array}{c}1163 \\
55\end{array}$ & 99,84 & 34,31 & 44,36 \\
\hline \multirow[b]{2}{*}{ IV } & & & & & & & $\begin{array}{l}\text { R.KMIQC(+5 } \\
\text { 7.02)ANKGS } \\
\text { R.A }\end{array}$ & 431,554 & $\begin{array}{c}1291 \\
65\end{array}$ & 97,92 & 37,83 & - \\
\hline & & & & & & & $\begin{array}{c}\text { K.SKC }(+57.0 \\
2) K D F V C(+5 \\
7.02) A C(+57 \\
.02) \text { DAAAAK } \\
\text {.C }\end{array}$ & 601,274 & $\begin{array}{c}1800 \\
8\end{array}$ & 97,82 & 33,65 & - \\
\hline \multirow{2}{*}{ IV } & $\begin{array}{c}\text { P04056|PA2 } \\
\text { BB_PSEAU }\end{array}$ & 84,74 & 19 & 2 & 12966 & $\begin{array}{c}\text { Basic phospholipase } \\
\text { A2 PA-11 } \\
\text { OS=Pseudechis } \\
\text { australis } \mathrm{PE}=1 \mathrm{SV}=1\end{array}$ & $\begin{array}{c}\text { N.MIQC(+57 } \\
.02) A N K G S R . \\
\text { P }\end{array}$ & 582,775 & $\begin{array}{c}1163 \\
55\end{array}$ & 99,84 & 34,31 & 44,36 \\
\hline & & & & & & & $\begin{array}{l}\text { K.SFVC }(+57 . \\
02) A C(+57.0 \\
\text { 2)DAAAAK.C }\end{array}$ & 635,778 & $\begin{array}{c}1269 \\
55\end{array}$ & 99,84 & 41,09 & 43,65 \\
\hline
\end{tabular}




\begin{tabular}{|c|c|c|c|c|c|c|c|c|c|c|c|c|}
\hline IV & $\begin{array}{c}\text { Q7LZG5|PA } \\
\text { 2_NOTSC }\end{array}$ & 61,41 & 50 & 1 & 2188 & $\begin{array}{c}\text { Phospholipase A2 II- } \\
5 \mathrm{~b} \text { (Fragment) } \\
\text { OS=Notechis } \\
\text { scutatus scutatus } \\
\text { PE=1 SV=1 }\end{array}$ & $\begin{array}{c}\text { NLIQLSNMIK } \\
. C\end{array}$ & 587,332 & $\begin{array}{c}1172 \\
66\end{array}$ & 99,65 & 31,74 & 38,29 \\
\hline IV & $\begin{array}{c}\text { P20260|PA2 } \\
\text { C_PSEPO }\end{array}$ & 61,41 & 36 & 1 & 3210 & $\begin{array}{c}\text { Phospholipase A2 } \\
\text { pseudexin C chain } \\
\text { (Fragment) } \\
\text { OS=Pseudechis } \\
\text { porphyriacus PE=1 } \\
\text { SV }=1\end{array}$ & & & & & & \\
\hline IV & $\begin{array}{l}\text { P59069|PA2 } \\
\text { SC_AUSSU }\end{array}$ & 61,41 & 22 & 1 & 4992 & $\begin{array}{c}\text { Phospholipase A2 } \\
\text { superbin c } \\
\text { (Fragment) } \\
\text { OS=Austrelaps } \\
\text { superbus PE=1 SV=1 }\end{array}$ & & & & & & \\
\hline IV & $\begin{array}{c}\operatorname{tr}|\mathrm{Q} 45 Z 18| \\
\text { Q45Z18_PSE } \\
\text { AU }\end{array}$ & 61,41 & 7 & 1 & 15939 & $\begin{array}{c}\text { Phospholipases } \\
\text { Pa-20 } \\
\text { OS=Pseudechis } \\
\text { australis } \mathrm{PE}=2 \mathrm{SV}=1\end{array}$ & & & & & & \\
\hline IV & $\begin{array}{c}\operatorname{tr|D5MRR3|} \\
\text { D5MRR3_9S } \\
\text { AUR }\end{array}$ & 61,41 & 7 & 1 & 15893 & $\begin{array}{c}\text { Phospholipase A2 } \\
\text { enzyme } \\
\text { OS=Pseudechis cf. } \\
\text { australis HI-2009 } \\
\text { GN=Pr-9 PE=2 SV=1 }\end{array}$ & & & & & & \\
\hline
\end{tabular}




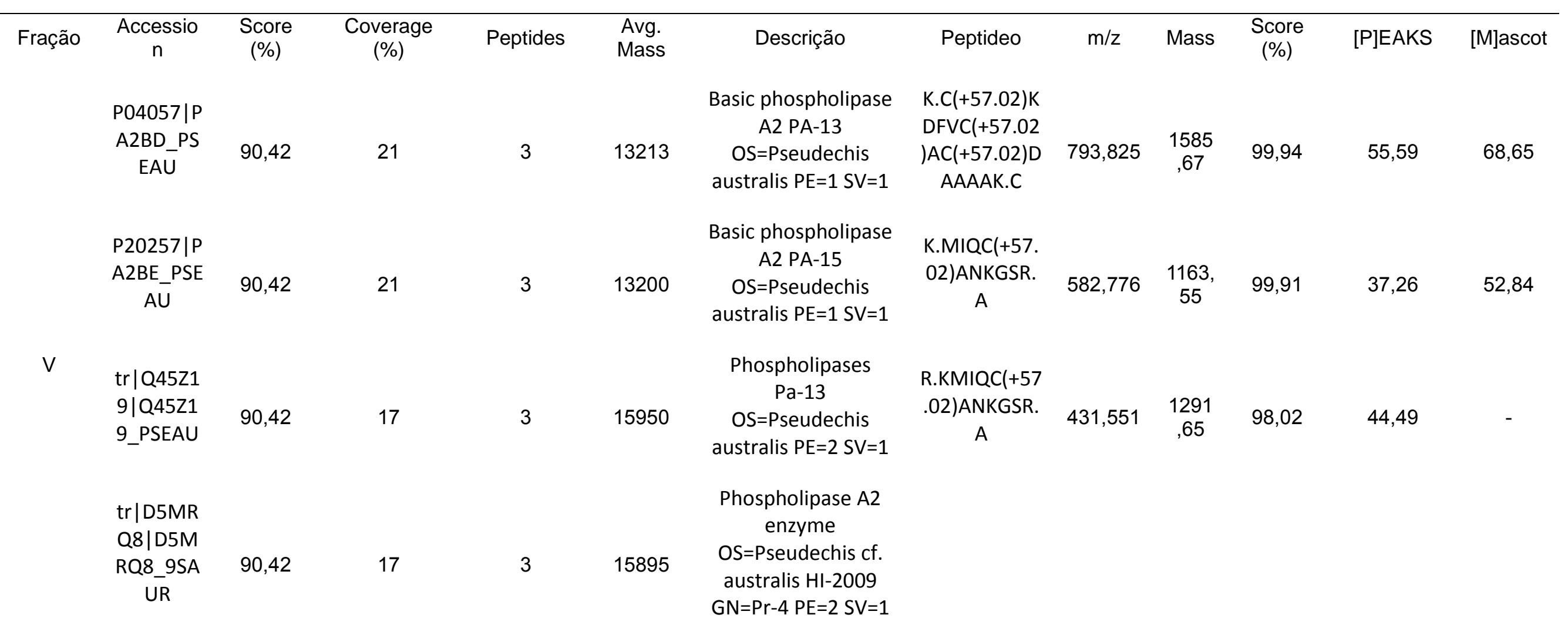




\section{DISCUSSÃO}

Os venenos de serpentes da família Viperidae tem sido amplamente estudados no que diz respeito a sua composição, aplicação medica e farmacológica. Por outro lado, pouco se sabe sobre os venenos das serpentes australianas (Elapidae), que são extremamente tóxicos (GEORGIEVA et al., 2011). $O$ isolamento geográfico do continente australiano certamente propiciou mecanismos evolutivos únicos para adaptação das serpentes às condições ambientais e aos tipos de presas disponíveis. Tal fato certamente propiciou $\mathrm{o}$ aparecimento de componentes do veneno específicos para a predação e sobrevivência neste ambiente, por meio de seleção natural. A alta toxicidade destes venenos também sugere que as toxinas que os compõem sofreram um progressivo refinamento, ficando mais potentes que toxinas homólogas de serpentes de outras regiões do globo Para exemplificar, a dose letal $50 \%$ (DL50) da crotoxina, uma PLA2 da cascavél sul-americana considerada altamente tóxica é de $0,05 \mu \mathrm{g} / \mathrm{kg}$ (Aird e Kaiser, 1985) ao passo que a taipoxina, PLA2 da serpente Australiana Oxyuranus scutellatus apresenta uma $\mathrm{DL}_{50}$ de apenas $0,009 \mu \mathrm{g} / \mathrm{kg}$ (Folhman et al, 1976). Assim são grandes as chances de haver nos venenos de serpentes Australianas toxinas novas e/ou mais potentes com possível aplicação biotecnológica.

A Pseudechis australis é uma serpente terrestre e tem uma distribuição geográfica muito ampla, podendo ser encontrada em quase todo continente (RAZAVI et al., 2014). Em decorrência desta abundância do animal, vários estudos já foram realizados com este veneno e alguns de seus componentes (JOHNSTON et al., 2013).

A glândula de serpentes venenosas estoca uma grande quantidade de toxinas, proteínas e peptídeos para deter predadores e matar suas presas. No entanto, existem mecanismos de proteção para que essas mesmas toxinas não afetem a própria glândula, sendo que numerosos inibidores de enzimas que podem ser responsáveis por esta estabilidade já foram descritos (MACKESSY \& BAXTER, 2006).

Ao fracionarmos o veneno total em uma coluna de exclusão molecular, a absorbância foi monitorada em dois comprimentos de onda (220 e 280nm), as 
ligações peptídicas são detectadas através da leitura em 220nm e aminoácidos que apresentam em sua composição anéis aromáticos absorvem em 280nm.

No cromatograma da figura 2, são observados três picos que apresentam diferentes volumes hidrodinâmicos sendo que o pico I apresenta maior massa molecular e melhor separação. No pico II foi observado a menor absorbância em $280 \mathrm{~nm}$, quando comparada aos picos adjacentes. O pico III apresentou a maior absorbância no mesmo comprimento de onda, sendo, portanto, a fração majoritária presente neste perfil cromatográfico.

$\mathrm{Na}$ eletroforese em Gel SDS - PAGE 15\% realizada com os picos coletados, observa-se diferenças na disposição das bandas de um mesmo pico, ao utilizarmos tampões de amostra redutor e não redutor, indicando a presença de proteínas multiméricas no veneno de $P$. australis. No pico I são observadas duas bandas que apresentam massas moleculares de aproximadamente $60 \mathrm{kDa}$ e $45 \mathrm{kDa}$. Na amostra referente ao pico II é observado a presença de somente uma banda isolada de aproximadamente $45 \mathrm{kDa}$. E no pico III foram observadas bandas de aproximadamente $18 \mathrm{kDa}$ e 14kDa. Georgieva e colaboradores (2011) descrevem que proteínas com massa molecular entre $60 \mathrm{kDa}$ e $40 \mathrm{kDa}$ são em sua maioria metaloproteases e aqueles com massa molecular entre 20 e $15 \mathrm{kDa}$ são majoritariamente fosfolipases. Estudos realizados pelos mesmos autores mostram que as metaloproteases no veneno da $P$. australis são amplamente representadas correspondendo a $53 \%$ das toxinas identificadas. No entanto, esta análise é enviesada uma vez que a quantificação relativa foi feita contabilizando o número de spots identificados como metaloproteases em relação ao total de spots analisados, desconsiderando a intensidade dos spots. Assim um único spot intenso correspondendo a uma dada proteína tem peso menor no cálculo do que vários spots tênues.

Metaloproteases de veneno de serpentes compreendem uma série de enzimas zinco-dependentes que apresentam massa molecular variável e são responsáveis pelos efeitos hemorrágicos provocados pelo envenenamento por serpentes (KAMIGUTI, ZUZEL \& THEAKSTON, 1998). Com a realização do ensaio de zimografia, pudemos observar duas bandas distintas do pico II. Utilizando um quelante de cátions divalentes (EDTA), uma dessas bandas foi inibida, sugerindo que essa banda é uma metaloprotease. Outro inibidor, desta vez para serinoproteases (PMSF), e a banda que não tinha sofrido inibição pelo 
EDTA foi inibida, indicando que essa banda é uma serinoprotease. Tal fato é digno de nota, uma vez que até o presente momento, não há nenhuma descrição na literatura sobre serinoproteases no veneno de Pseudechis australis.

As serinoproteases são enzimas proteolíticas que tem uma histidina, um ácido aspártico e uma serina como tríade catalítica com este último aminoácido atuando como nucleófilo. Estas enzimas são ubíquas e formam a maior família das peptidases (RAWLINGS \& BARRETT, 1993). No veneno das serpentes, afetam o sistema hemostático agindo em uma variedade de componentes da cascata de coagulação, provocando um desequilíbrio no sistema hemostático (SEEGERS \& OUYANG, 1979). O possível papel de serinoproteases no envenamento por $P$. australis ainda é obscuro, mas, por similaridade com outros venenos, acreditamos que esteja ligado a hemostasia.

As elapidaes contém um vasto número de peptídeos farmacologicamente ativos, com um amplo leque de ações nas funções fisiológicas e com isso podendo se tornar uma abundante fonte de biomoléculas para a criação de protótipos de novos medicamentos (MUNAWAR et al., 2014).

O potencial destes peptídeos vem sendo explorado pela indústria farmacêutica que têm investido nas pesquisas de peptídeos dos venenos de serpentes, gerando novos fármacos. Aproximadamente 60 fármacos a base de peptídeos já estão no mercado (BOGIN, 2005) e movimentaram 13 bilhões de dólares em 2010 (THAYER, 2011). No ano de 2011, peptídeos representavam $2 \%$ dos fármacos no mercado e totalizavam $50 \%$ das drogas em estudo (pipeline) dos fabricantes (KING, 2011). Abaixo (tabela 3) estão listados alguns fármacos que estão sendo estudados ou que já foram aprovados pela FDA (Food and Drug Administration.

Tabela 3: Fármacos que são derivados dos venenos de serpentes

\begin{tabular}{cccccc}
\hline Fármaco & Espécie & Alvo Molecular & Doença & $\begin{array}{c}\text { Estagio } \\
\text { clinico }\end{array}$ & Companhia \\
\hline \multirow{2}{*}{ Ancrod } & $\begin{array}{c}\text { Agkistrodon } \\
\text { rhodostoma }\end{array}$ & $\begin{array}{c}\text { Inibidor de } \\
\text { fibrinogenio }\end{array}$ & $\begin{array}{c}\text { Trombocitopenia } \\
\text { induzida por } \\
\text { heparina }\end{array}$ & Fase III & $\begin{array}{c}\text { Neurobiological } \\
\text { Industries Inc. } \\
\text { (www.ntii.com) }\end{array}$ \\
& $\begin{array}{c}\text { Bothrops } \\
\text { Captopril }\end{array}$ & $\begin{array}{c}\text { Enzima } \\
\text { Conversora de } \\
\text { angiotensina }\end{array}$ & $\begin{array}{c}\text { Anti- } \\
\text { hipertensivo }\end{array}$ & $\begin{array}{c}\text { Aprovado } \\
\text { pela FDA }\end{array}$ & $\begin{array}{c}\text { Bristol-Myers } \\
\text { Squibb }\end{array}$ \\
& & & & (www.bms.com)
\end{tabular}


(ACE)

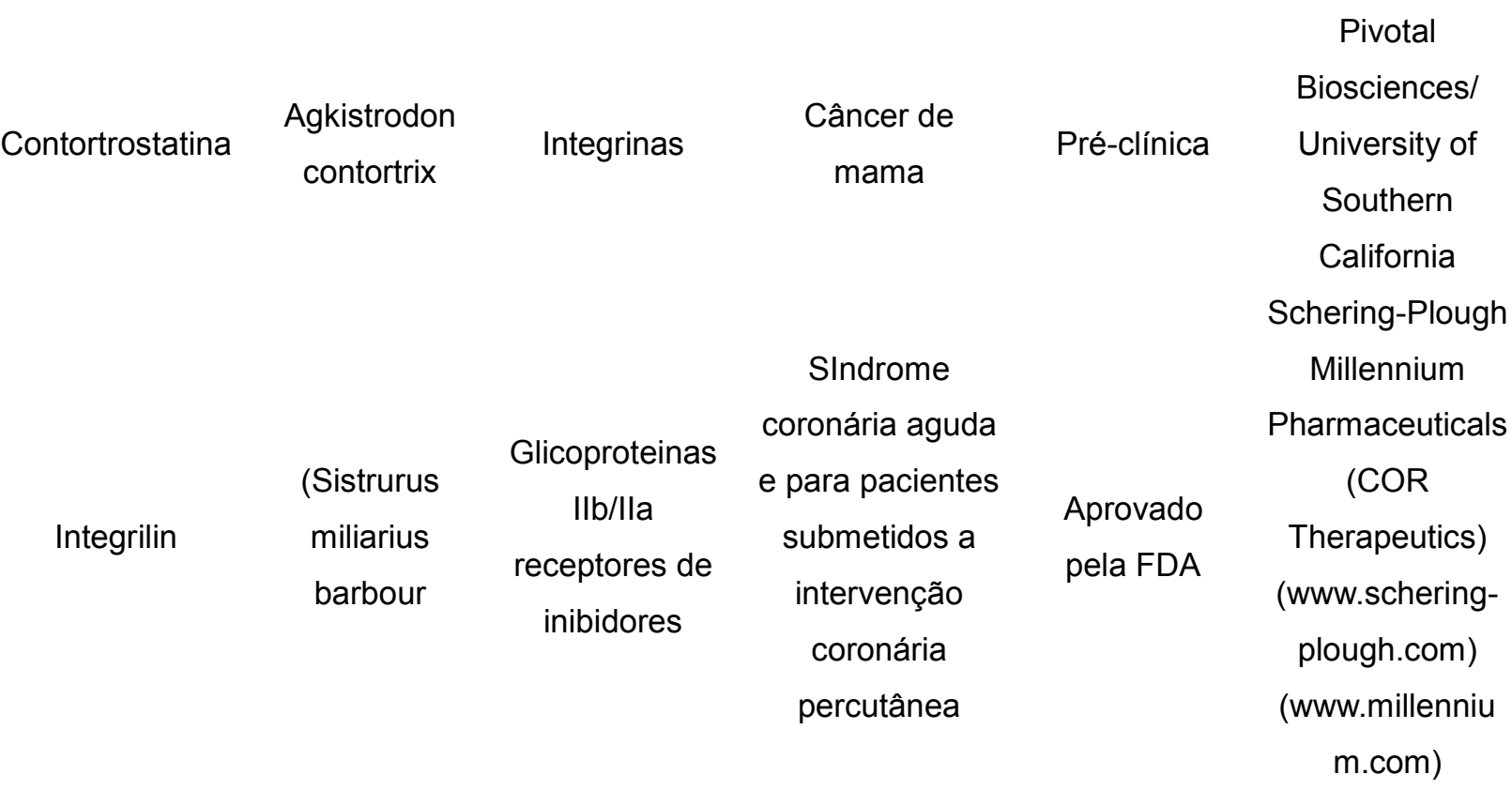

No presente trabalho, ao centrifugar o veneno total usando uma membrana Centricon $®$ de $10 \mathrm{kDa}$, houve uma separação dos comonentes de alta e baixa massa. As moléculas de baixa massa foram introduzidas no espectrômetro de massa para análise. Os dados obtidos passaram por uma busca em bancos de dados usando uma ferramenta de alinhamento e identificação de sequencias por similaridade BLAST (Basic Local Alignement Search Tool), disponível em diversos sites. Dos peptídeos sequenciados com score de confiança alto, apenas $1(E Q Q Q)$ alinhou com uma sequencia já descrita nos bancos de dados de veneno de serpentes. Este fragmento corresponde a uma região do pró-peptídeo do peptídeo natriurético de Oxyuranus scutellatus scutellatus (uniprot accession:P83228) uma espécie Australiana próxima de $P$. australis. Este dado sugere que além do peptídeo ativo, resquícios do processamento do pró-peptídeo foram identificados. A identificação deste fragmento pós-processamento no veneno levanta a hipótese de uma possível função biológica deste tetrapeptídeo. Os outros peptídeos sequenciados não produziram alinhamentos satisfatórios, mesmo utilizando ferramentas de busca mais permissivas nos bancos de dados. Este fato indica tratar-se de moléculas sem similaridade com qualquer outra de veneno disponível nos bancos. Isto é bastante comum para espécies pouco estudadas já que a identificação de uma proteína por sequenciamento de novo associado 
a bioinformática está atrelada à existência de sequências similares disponíveis em bancos de dados para as ferramentas de busca e alinhamento.

Ao analisar as moléculas de maior massa, as buscas resultaram apenas em fosfolipases.

Estas proteínas são enzimas ubíquas, intra e extracelulares, e desempenham um importante papel em várias atividades biológicas como proliferação celular e inflamação. As fosfolipases de venenos tem um vasto leque de funções como por exemplo, neurotoxicidade, miotoxicidade, atividade hemolítica, hemorrágica entre outras (KINI, 2003).

A dificuldade em identificar as proteases objetos deste estudo por espectrometria na fração de maior massa pode ser atribuída a alta concentração de fosfolipases nesta fração. Conforme já explicitado acima, o instrumento tende a priorizar os analitos com maior sinal (intensidade relativa), em detrimento de outros com sinal mais fraco. Assim, este sinal mais intenso mascara a presença de íons minoritários.

A proposta inicial deste trabalho era de isolar e caracterizar tanto as proteases quanto os inibidores endógenos destas enzimas do veneno de $\mathrm{P}$. australis. Foram identificadas 2 proteases com atividade fibrinogenolítica sendo uma destas uma serinoprotease ainda não descrita na literatura. Em experimentos posteriores buscaremos obter esta molécula na forma pura para melhor caracterização. Os peptídeos sequenciados são desconhecidos, com exceção do tetrapeptídeo EQQQ que é parte do pró-peptídeo natriurético. Uma eventual atividade biológica deste tetrapeptídeo está sendo investigada. 


\section{CONCLUSÃo}

- Na cromatografia de exclusão molecular, picos do veneno da Pseudechis australis foram separados.

- Na eletroforese, os picos coletados foram analisados e apenas nos picos I e ll observamos a presença de bandas com massa similar.

- Método fluorimétrico de detecção e quantificação de atividade caseinolítica foi padronizado

- O pico II mostrou maior fluorescência comparado aos outros picos no ensaio fluorimétrico

- No ensaio de zimografia, obtivemos 2 bandas do pico II e utilizando inibidores específicos, caracterizamos uma metaloprotease e uma serinoprotease do veneno da $P$. australis, sendo que até o presente momento nenhuma serinoprotease desse veneno havia sido descrita na literatura.

- No ensaio fibrinogenolítico, houve clivagem da cadeia alfa e beta.

- Foi identificado um peptídeo com sequência EQQQ, previamente descrito no veneno de Oxyuranus scutellatus scutellatus.

- Na identificação das proteínas de alta massa dos picos III, IV e V, nenhum resultado de protease foi obtido, apenas fosfolipases que possam estar mascarando sinais de algumas toxinas. 


\section{REFERÊNCIAS}

Agarwal, A.; Tressel, S.L.; Kaimal, R.; Balla, M.; Lam, L.H.; Covic, L.; Kuliopulos, A. Identification of a metaloprotease-chemokine signaling system in the ovarian câncer microenvironment: implications for antiangiogenic therapy. 2010. Cancer Res., 15;70(14):5880-90

Aird, S.D., and Kaiser, I.I., Comparative studies on three rattlesnake toxins. 1985. Toxicon., 23, 361-374.

Australian Reptile Park. http://www.reptilepark.com.au/animalprofile.asp?id=113. Acessado em 24/02/2015.

Bieber, A.L.; Nedelkov, D. Structural, biological and biochemical studies of myotoxin and homologous myotoxin. 1997. J. Toxicol- Toxin Ver.16, pp. $32-52$

Birrell, G.W.; Earl, S.T.H.; Wallist, T.P.; Masci, P.P.; Jersey, J.; Gorman, J.J.; Lavin, M.F. The diversity of bioactive proteins in Australian snake venoms. 2007. Molecular \& Cellular Proteomics 6.6

Bogin, O. Venom peptides and their mimetics as potential drugs. 2005. Modulator $n^{\circ} 19$. www.alomone.com

Calvette, J.J.; Sanz, L.; Angulo, Y.; Lomonte, B.; Gutiérrez, J.M. Venoms, venomics, antivenomics. 2009. FEBS Letters 583 1736-1743

Collins, C.H. Separações em colunas abertas: cromatografia por exclusão e por bioafinidade. 2011. Scientia Chromatohraphica 3(2) 107-114

Cunha, E.M.; Martins, O.A. Principais compostos químicos presentes nos venenos de cobras do gênero Bothrops e Crotalus - Uma revisão. 2012. Revista eletrônica de educação e ciência. Vol 2. № 2

Davis, R.A.H. Aspectos proteômicos e determinação de elementos traço em bílis de peixe: potencial marcador biológico de exposição ambiental? Tese de doutorado. 2012 
Francis, B.; Kaiser, I.I.; Inhibition of metaloproteinases in Bothrops asper Venom by endogenous peptides. 1993. Toxicon.; 31(7):889-99

Fohlman J, Eaker D, Karlsoon E, Thesleff S. Taipoxin, an extremely potent presynaptic neurotoxin from the venom of the australian snake taipan (Oxyuranuss. scutellatus). Isolation, characterization, quaternary structure and pharmacological properties.1976. Eur. J. Biochem. 15;68(2):457-6

Funasa - Fundação Nacional de Saúde. Manual de diagnóstico e tratamento de acidentes de animais peçonhentos. 2001. $2^{\circ}$ Ed. Brasília

Gonçalves, J.M. Estudos sobre venenos de serpentes brasileiras. II Crotalus terrificus crotaminicus, subespécie biológica. 1956. NA. Acad. Brasileira Ciencias, 28, pp. 365-367

Hodgson, W.C.; Wickramaratna, J.C. Snake Venom and their toxins: An Australian perpective. 2006. Toxicon 48 931-940

Johnston, C.I.; Brown, S.G.A.; O'Leary, M.A.; Currie, B.J.; Greenberg, R.; Taylor, M.; Barnes, C.; White, J.; Isbister, G.K. Mulga snake (Pseudechis australis) envenoming: a spectrum of miotoxicity, anticoagulante coagulopathy, haemolysis and the role of early antivenom therapy Australian Snakebite Project. 2013. Clinical Toxicology 53, 417-424.

Kamiguti, A.S.; Zuzel, M.;Theakston, R.D.G. Snake venom matelloproteinases and desintegrins: interactions with cells. 1998. Brazilian Journal of Medical and Biological Research 31: 853-862

King GF. Venoms as a platform for human drugs: translating toxins into therapeutics. 2011. Expert Opin Biol Ther. 11:1469-84.

Kini, R.M. Excitement ahead: structure, function and mechanism of snake venom phospholipase A2 enzymes. 2003. Toxicon vol. 42: 827-840

Klein, T.; Bischoff, R. Physiology and pathophysiology of matrix metaloproteases. 2010.2 Amino Acids. http://www.springerlink.com/content/ j78n2p8610270184/fulltext.pdf. Acessado em 29/10/2014 
Laure, C.J. Die Primärstruktur des Crotamines. 1975. Hoppe-Seyler's Z. physiol. Chem. 356, pp. 213-215.

Luft, F.C. The Bothrops legacy: vasoactive peptides from Brazil. 2008. J Renin Angiotensin Aldosterone Syst. ,9(1):57-64

Mackessy, S.P.; Baxter, L.M. Bioweapons synthesis and storage: The venom gland of front-fanged snakes. 2006. Zoologischer Anzeiger 245 147-159.

Marques-Porto, R.; Lebrun, I.; Pimenta, D.C. Self-proteolysis regulation in the Bothrops jararaca venom: The metallopeptidases and their intrinsic peptidic inhibitor. 2008. Science Direct. Elsevier. Brazil

Munawar, A.; Trusch, M.; Georgieva, D.; Hildebrand, D.; Kwiatkowski, M.; Behnken, H.; Harder, S.; Arni, R.; Spencer, P.; Schlüter, H.; Betzel, C. Elapid snake venom analyses show the specificity of the peptide composition at the level of genera Naja and Notechis. 2014. Toxins 6, 850868

Pierre, L.S.; Flight, S.;Masci, P.P.; Hanchard, K.J.; Lewis, R.J.; Alewwod, P.F.; Jersey, J.; Lavin, M.F. Cloning and characterisation of natriuretic peptides from the venom glands of Australian elapids. 2006. ScienceDirect Biochime 881923 - 1931

Rawlings, N.D.; Barrett, A.J. Evolutionary families of peptidases. 1993. Bioche.J., v. 290, p. 205-218

Razavi, S.; Weinstein, S.A.; Bates, D.J.; Alfred, S.; White, J. The Australian mulga snake (Pseudechis australis: Elapidae): Reporto f a large case series of bites and review of current knowledge. 2014. Toxicon 85 17-26

Ritonja, A.; Meloun, B.; Gubensek, F. The primary structure of Vipera ammodytes Venom trypsin inhibitor I. 1983. Biochim. Biophys. Acta 748:429-435

Seegers, W.H.; Ouyang, C. Snake venoms and blood coagulation Handbook of experimental pharmacology. 1979. 52: 684-750 
Silva, A.C.S.; Pinheiro, S.V.B.; Santos, R.A.S. Peptideos e interação coração-rim. 2008. Rev. Bras. Hipertens vol. 15(3): 134-143

Thayer A. M. Improving peptides. 2011. Chemical \& Engineering news 89 (22), 13-20.

Wildscreen Arkive. King brown snake. http://www.arkive.org/king-brownsnake/pseudechis-australis/. Acessado 23/02/2015

Williams, D.; Wüster, W.; Fry, B.G. The good, the bad and the ugly: Australian snake taxonomists and a history of the taxonomy of Australia"s venomous snake. 2006. Toxicon 48 919-930 